ISSN: $1130-3743$

\title{
EPISTEMOLOGÍA PEDAGÓGICA (II)
}

\section{PEDAGOGICAL EPISTEMOLOGY (II)}

\author{
JOAQUÍN GARCÍA CARRASCO, ÁNGEL GARCÍA DEL DUJO \\ Universidad de Salamanca. Departamento de Teoría e Historia de la Educación. Facultad \\ de Educación. Paseo de Canalejas, 169. 37008 Salamanca.
}

\section{RESUMEN}

En este artículo los autores analizan dos tipos de cuestiones: los presupuestos ontológicos y los problemas gnoselógicos que conlleva la construcción de la Pedagogía en cuanto campo de conocimientos sobre los fenómenos educativos. Desde la perspectiva de los sistemas dinámicos, y distinguiendo en educación entre lo que podemos llamar procesos adaptativos primarios, vitalmente necesarios, y aquellos otros componentes o niveles propios de la evolución cultural, los autores concluyen en la necesidad no sólo de adoptar formas plurales de conocimiento y hasta pluralidad de ciencias sino también de tomar en consideración aspectos tales como la emoción, la sensibilidad, la afectividad para un análisis global de los procesos educativos. El artículo termina, en consecuencia, con una propuesta global de caracterización epistemológica de la Pedagogía y, como contrapunto, una visión analítica de lo que los autores denominan realismo pedagógico ingenuo.

SUMMARY

In this article the authors study two kinds of questions: the ontological assumptiones and the constructing the Pedagogy problems as a field of knowledge about educational phenomena. In view of the dynamic systems, and distinguishing in education the primary process of adaptation, vitally necessary, from another typical components or levels of the cultural development, the authors think it's necessary not only to assume a lot of forms of knowledge and sciences but to bear in mind aspects just as the emotion, the sensibilty, the affectivity for a comprehensive study of educational process. The article finish, therefore, with a global epistemological caracterization of the Pedagogy and, as contraposition, a analytical view of that the authors call pedagogical ingenuous realism. 


\section{INTRODUCCIÓN}

En el artículo anterior ${ }^{1}$ planteábamos los fundamentos para una epistemología pedagógica. Tal planteamiento se apoyaba en varios supuestos o postulados previos: la diferenciación entre procesos educativos y discursos educacionales (entre realidad y texto), la distinción entre acción educativa y acción pedagógica (entre procesos educacionales y diseños pedagógicos). Allí afirmábamos que la Pedagogía se construye partiendo de la observación y discusión de los sucesos, acontecimientos, procesos educacionales de todo tipo, los cuales en la especie humana constituyen un conjunto de caracteres comportamentales necesarios para el desenvolvimiento del comportamiento humano. La Pedagogía nace como discurso sobre la educación, como reflexión en y sobre la educación. Y describíamos las grandes corrientes de pensamiento respecto a la reconstrucción de tales discursos en las ciencias humanas y en particular en la Pedagogía.

De manera especial nos detuvimos en tres puntos: la crítica del monismo metodológico que caracteriza a la epistemología positivista; la descripción etnográfica de un campo de conocimientos, cualquiera que sea el sistema de acontecimientos (físicos, biológicos o mentales) sobre los que recaiga y la descripción del propio proceso de observación cuando el sujeto queda epistemológicamente implicado tanto en la acción de observación como en el acontecimiento observado.

En esta ocasión nos referiremos a problemas de ontología pedagógica, y consecuentemente, a cuestiones metodológicas de carácter general. También aquí nuestra reflexión se construye desde una perspectiva sintética, es decir, desde una revisión de contenidos del discurso pedagógico que permita, por encima de discusiones de escuela, recoger los materiales de la corriente central de pensamiento, de forma que sea posible hacerse una idea de hasta donde parece que se ha avanzado.

\section{PRESUPUeStOS ONTOLÓGicos}

\subsection{Presupuestos sistémicos generales}

Las relaciones entre los seres vivos no se reducen meramente a relaciones de posición, extensión o distancia, por lo que el concepto físico y geométrico de espacio resulta insuficiente cuando pretendemos analizar su comportamiento. Ya en los entes físicos (una roca, el agua) se producen, en determinadas circunstancias, cambios no meramente posicionales, sino que implican también cambios de estado y transformaciones (oxidación, combinación, descomposición ...); y en los seres vivos se dan interacciones entre unos y otros (organismos o poblaciones) a través de las cuales tienen lugar intercambios materiales (nutrientes, componentes genéticos, indicios físicos o químicos, agresiones) o simbólicos (señales, lenguaje).

1. García Carrasco, J. y García Del Dujo, A.: "Epistemología pedagógica (I)", Teoría de la Educación. Revista Interuniversitaria 7 (1995) 5-38. 
Pues bien, entendemos por sistema todo conjunto de elementos organizados que actúan unos sobre otros y en el que puede ser definido un comportamiento global. Estas propiedades globales son las que permiten considerar como sistema a la célula, al sistema nervioso formado por células neuronales, al organismo humano que es capaz de expresarse y a una comunidad humana capaz de organizarse democráticamente, lo que hace posible incluso hablar de propiedades ambientales al referirnos al hombre y su entorno. Además podemos decir que para todo sistema dinámico finito existe un entorno compuesto por el conjunto de entidades materiales (físicas, biológicas), institucionales o simbólicas con las que interactúa.

En los ejemplos anteriores se advierte que la fragmentación del sistema o su integración en unidades superiores depende de la existencia-emergencia de propiedades específicas irreductibles a unidades sistémicas inferiores; la reproducción sexual no puede darse en sistemas unicelulares, los intercambios simbólicos requieren al menos una díada de individuos, el mecanismo de la transmisión cultural requiere comunidades de individuos... Un sistema de educación está mínimamente constituido por una tríada de subsistemas (educador, educando y situación, en todas sus formas y concreciones) y pueden definirse en ella propiedades sistémicas (propiedades de la tríada, aunque lo habitual es analizar los elementos por separado o por relaciones diádicas); la comunicación y sus propiedades son propiedades sistémicas. En el caso de la Pedagogía la noción de sistema es fundamental ontológicamente porque los procesos educacionales, aunque supongan cambios en propiedades de sujetos individuales, tales cambios son consecuencias de procesos sistémicos de carácter relacional. La epistemología pedagógica responde a una ontología relacional: el sujeto educativo se instituye dentro de esa misma relación y el proceso educativo lo es en un sistema de relaciones. Por la misma razón, constituirá sistema educativo tanto la relación materno/paterno-filial como la relación educador/a-educando, o la relación entre hermanos, la relación entre iguales...

Si la fragmentación sistémica es criterial (se lleva a cabo en función de un criterio de demarcación) y si el concepto mismo de sistema, en nuestro caso, implica interacción con un entorno, cabe la posibilidad de encontrar una propiedad o función que conecte un sistema dado y una parte de su entorno y que defina un nuevo sistema con propiedades globales; ello quiere decir que tanto un/os siste$\mathrm{ma} / \mathrm{s}$ puede/n ser entorno/s de otro/s sistemas como constituir a su vez sistemas de mayor magnitud y definir sus correspondientes entornos. Plantear un criterio de demarcación sistémica es análogo a tomar perspectiva de observación; en el espacio de un aula podemos tomar el criterio de observar el comportamiento del profesor respecto al cual el grupo de alumnos es entorno, o el del grupo para el que el profesor es entorno, o el sistema profesor-estudiante/s... En todos los casos nos referimos a sistemas y sus correspondientes propiedades sistémicas, son sistemas con sujetos.

Esta aparente obviedad tiene su importancia cuando se estudian determinados conjuntos de sistemas. Por ejemplo, es claro que una escuela está formada por profesores y alumnos; la demarcación entre el sistema profesor y el sistema alum- 
nos resalta a primera vista, pero requiere cierta capacidad de abstracción discurrir sobre el profesor en tanto que referente del sistema de los alumnos (su entorno), o componente con ellos (sistema de enseñanza-aprendizaje) y constituyendo, por lo mismo, una condición para el aprendizaje de éstos y, a la inversa, constituyendo los alumnos un factor importante de influencia sobre el comportamiento del profesor. Es decir, cabe definir propiamente el sistema educador-educandos y apreciar propiedades y procesos de tal sistema, v. gr., el proceso curricular no tendría sentido sin esta unidad sistémica mínima. Con ello queremos indicar que el concepto de entorno o ambiente está en función de la aplicación de un criterio de demarcación que determine el sistema a considerar, por ejemplo, para un individuo de una especie determinada es entorno el conjunto de individuos de su propia especie, los de otras especies y los componentes del medio físico con los que interactúa.

La distinción entre sistema y entorno hace, pues, pertinente tener en cuenta la definición de límites de los sistemas ${ }^{2}$. Ya hemos indicado que la delimitación de un sistema se produce mediante la aplicación de un criterio de demarcación, el cual no es sino el reverso del enunciado mediante el que se declaran las propiedades globales o propias de la unidad sistémica definida; el ámbito de referencia o aplicación de la propiedad señala los límites del sistema. Ello tiene interés, a su vez, tanto para la definición de sistema como para la de entorno o ambiente; en general puede decirse que las relaciones que median entre los elementos del entorno con el sistema considerado son diferentes a las relaciones que median entre los componentes internos del sistema. Son observables claramente las diferencias entre las relaciones de los alumnos entre sí y las relaciones que estos mantienen con $\mathrm{su} / \mathrm{s}$ educadores.

Hemos puesto de manifiesto lo esencial que es para la definición de sistema y de su entorno la propiedad general que podríamos denominar exterioridad, que no es otra cosa distinta del comportamiento del sistema en un entorno determinado. Ello implica que el comportamiento de un sistema se configura y cambia en entornos diferentes, lo que puede corroborarse con múltiples observaciones. Y si la permanencia de un sistema está en función del mantenimiento de la organización interna del mismo y de las interacciones necesarias y suficientes de éste con su entorno, las modificaciones del entorno pueden actuar en sentido benéfico o perjudicial; e incluso, cuando un sistema se ve obligado a cambiar de entorno, pueden aparecer problemas de adecuación o inadecuación tales que se produzca la evolución o la desaparición. Dicho en otros términos: el comportamiento de un sistema puede quedar afectado por intervenciones directas sobre el mismo o sobre su entorno: alterar las condiciones en el entorno también es influir sobre los sistemas correspondientes, es una exigencia lógica de la teoría y una consecuencia que se corrobora mediante la observación. En nuestro caso, la acción de formación termina afectando al comportamiento tanto si va dirigida a alguno de los componentes del sistema como si se orienta a las condiciones que caracterizan el

2. ARACIL, J. (1978): Introducción a la dinámica de sistemas. Ed. Alianza Universidad, Madrid.

(C) Ediciones Universidad de Salamanca

Teor. educ. 8,1996 , pp. 5-42 
entorno. Entrar en un entorno es ya, por principio, afectarlo; crear entornos culturales constituirá una acción de formación.

Por último, en el caso del ser humano, la definición de entorno impide que se pueda hacer abstracción de su carácter sociocultural y hace resaltar el inconveniente de reducirlo a parámetros, por ejemplo, de espacio físico construido; incluso en este caso las relaciones del hombre con el espacio físico tienen naturaleza sociocultural. Así, puede comprobarse cómo la vivencia en un espacio físico determinado condiciona las relaciones del individuo con los demás y las relaciones del individuo con el espacio físico en general; vivir en un medio rural tipifica modos de relación con los demás y peculiaridades en las relaciones con el espacio físico. Estos rasgos determinan la especificidad del espacio humano, el cual incluye junto a todos los demás componentes derivados de su condición de ser vivo la de ser cultural 3 .

\subsection{La mente en perspectiva sistémica}

La actividad mental humana contiene dos principios de garantía: hay cosas y ocurren cosas, es el principio del realismo, y, además, los sucesos del mundo no son independientes entre sí, ni tomados en un instante ni adoptando como marco de referencia el tiempo (poseen regularidad, causas parecidas producen efectos parecidos), es el principio determinista. El concepto de ley de la naturaleza es la consecuencia de los dos principios anteriores y contiene no sólo la idea de regularidad sino también la interdicción, pues no todo es posible. En las ciencias humanas la garantía del realismo se asume aceptando acontecimientos y su posibilidad de observación, la garantía de la determinación se contiene en la noción de condicionamiento; sin ambas cosas no podemos construir discursos científicos. Sin el condicionamiento ni siquiera es posible el pensamiento crítico, sin la creatividad del comportamiento no es posible la formación, formar es crear posibilidades; en la descripción del comportamiento humano caben los aspectos condicionados del comportamiento, los cuales permiten las ciencias del comportamiento, y los aspectos creativos e idiosincráticos del mismo.

Pues bien, esa mente humana, en lo que tiene de estructura bio-fisiológica y en lo que esa estructura tiene de función, es primariamente un producto de la evolución, ya que no tiene en su origen un proyecto cuya meta específica haya sido el ejercicio de la racionalidad tal y como ésta se entiende en los libros de epistemología, sino que, como en los demás seres vivos, es el producto de adaptacio-

3. A efectos de evitar malentendidos o ambigüedades definimos los siguientes términos: entorno físico natural —el entorno geológico y el atmosférico-climático-; entorno físico construido - el entorno domiciliario y urbano (vivienda, redes y medios de comunicación, urbanización, fábricas...) - ; entorno biológico natural -el entorno biológico (plantas y animales) propio de espacios físicos no modificados por la industria del hombre y los animales y las plantas que acompañan espontáneamente al hombre (aves, insectos...); entorno biológico construido -el propio de la industria agrícola, ganadera o derivado de procesos de domesticación-; entorno social —el conjunto de interacciones del hombre o la mujer con otros hombres y mujeres. 
nes múltiples a situaciones ambientales diferentes en las que nuestros antepasados vivieron a lo largo de su historia vital. La racionalidad así entendida se constituye como posibilidad tanto por parte de la disposición de la estructura como en la medida en la que los contextos socioculturales la hacen plausible; es decir, no se construyó evolutivamente la mente para ser lógica (la lógica de los tratados), sino para ser adaptativa. El hombre elabora pensamientos matemáticos y lógicos, siendo ésta una de sus capacidades, pero no la única e incluso ni siquiera aparece en la vida real como predominante; de hecho, también los filósofos y psicólogos - los profesores lo advierten continuamente- observan comportamientos en los que el hombre opera con Minimal Rationality (pensamiento débil), estrategias sencillas de decisión o de opinión en las que no existe argumento para pensar que la mente humana recorrió antes la totalidad de la tabla de decisión, ni siquiera parece que la situación proporcione tiempo vital para tales cometidos. Luego la modalidad de configuración del comportamiento en la situación, la decisión de acción, el sistema mental que la evolución ha dispuesto opera con finalidad predominantemente adaptativa y de integración en el entorno vital en el que ha de sobrevivir: desarrollarse, alimentarse, satisfacerse afectiva y emocionalmente, encontrar cobijo... La educación como proceso debería tener, pues, como objetivo primario la socialización del comportamiento y su potencial adaptativo en todos los órdenes; el contenido de la denominada educación formal se estructura así como un nivel secundario o derivado de la situación sociocultural de comunidades humanas situadas en ciertos niveles de desarrollo y con ciertos caracteres de su complejidad; por ejemplo, el carácter asumible de formalidad en las acciones de formación es diferente en sociedades ágrafas y en sociedades lectoescritoras, como lo será igualmente en sociedades muy telemáticas.

Un dato que viene a corroborar la reflexión anterior nos llega por el hecho de que el cerebro parece haber evolucionado fisiológicamente independientemente del aumento de la complejidad comportamental exigida por el entorno, como si no hubiera sido la consecuencia de las exigencias de la cooperación o del desarrollo del lenguaje, y miles de años antes de la aparición de la agricultura y de las pinturas rupestres, la tecnología o las muchas formas de discurso en las que quedan implicadas formas del silogismo...

Robert Orstein afirma a este respecto, apoyándose en estudios de otros autores y sorprendido por la interpretación de J. B. S. Haldane en 1986 de que el aumento del tamaño del cerebro hasta el volumen de homo sapiens es la transformación evolutiva más rápida que se conoce, que esta transformación "debió ser producto secundario de otra adaptación"... "no es probable que la causa de esta nueva complejidad anatómica estuviese en una adaptación cultural "4; su estímulo no fue social o cultural, sino fruto de adaptaciones relacionadas con ventajas fisiológicas del cerebro en su cápsula craneana; esas adaptaciones fisiológicas posibilitadas por la posición bípeda terminaron por seleccionar mayor número de neuronas, lo que aumentó tanto la posibilidad de restauración funcional en caso de

4. ORStein, R. (1991): La evolución de la conciencia. Los limites del pensamiento racional. Ed. EMECE, Barcelona. 
lesiones como la posibilidad de conexiones en paralelo, enlaces ampliados. Es la estructura de ordenamiento del sistema como consecuencia de la evolución, hace centenares de miles de años, la que, hoy, posibilita que dentro de la evolución cultural y no de la adaptativa estemos trabajando sobre inteligencia artificial. El cerebro no se adaptó para la actividad racional, sino para actividades sobrevivenciales en el entorno, como el resto de los animales; lo que es casualidad es que podamos ser lógicos, esto es un modo de utilización del potencial de inteligencia.

«....los cambios en la ingeniería (estructuración fisiológica) que pudieron producir un aumento radical de la corteza sin ninguna relevancia social importante o, según el vocabulario actual, sin ninguna razón relacionada con el proceso de información, podrían ser el fundamento de la clase de mente que poseemos: diversificada, no especializada y sorprendentemente plástica. Con muchas células ociosas en el momento del nacimiento y que pueden adoptar una gran cantidad de papeles" 5 .

Además, la pertenencia a una especie, y por lo mismo la condición específica humana, supone la incorporación en su estructura de las adaptaciones morfológicas que la selección decantó y de un cúmulo de pautas de reacción en el medio de origen adaptativo y no cultural. Por lo que el planteamiento de los empiristas (John Locke, David Hume, John Stuart Mill...) de que la mente humana nace como una tabla rasa o un papel en blanco no sería con rigor totalmente válido; no todo el conocimiento surge de la experiencia y, sobre todo, lo que une las experiencias creando encuadres mentales no es meramente la asociación entre ideas. El hombre nace dispuesto para la interacción con el medio, como también el afloramiento del campo emocional guía a lo largo del desarrollo el comportamiento en el medio.

En cualquier caso, el concepto de formación queda intrínsecamente asociado a la intersubjetividad, a la interacción; la prueba más evidente se encuentra en el hecho de que el aislamiento social después del nacimiento puede llegar a producir, si sobrevive el sujeto, consecuencias que lo hacen antropológicamente irreconocible. La mediación de tal interacción es triple y heterogénea: lenguaje, trabajo, comunidad (familia-grupo e instituciones sociales)... todo el sistema de comunicación entre sujetos que actúan y conviven. Mediante el lenguaje se ordena el caos de la sensación en constructos identificables; mediante el trabajo se ordena el caos de los deseos y necesidades del hombre en el mundo. En el lenguaje la mediación la establece el símbolo, en el trabajo la mediación la establece el instrumento, en el que queda sedimentada la experiencia y la iniciativa. Tanto el lenguaje como el trabajo consienten el reconocimiento histórico de la propia identidad en el tiempo y constituyen las condiciones en las que se conforma la universalidad: podemos pensar sobre lo mismo y desear lo mismo.

El lenguaje permite la objetividad que se expone-impone al espíritu; en el trabajo se mantiene la astucia mediante la que el espíritu se impone a la naturaleza. En el marco de los convencionalismos y las modas, por ejemplo, se produce una

5. IBIDEM, p. 77. 
aproximación categorial de la astucia del trabajo —satisfacción de necesidades mediante la producción de bienes de consumo- utilizando la mediación del lenguaje como contenedor de la astucia que justifica la moda. Este es un campo abonado para la crítica, pero de ello no se puede deducir la invalidación de toda acción estratégica, dado que hay que distinguir entre tipos ideales de acción y modos históricos de acción.

De todo ello podemos deducir algunas cuestiones interesantes para nuestro objetivo. De un lado, que las posibilidades de planteamiento científico sobre la educación no solamente se obtienen de las aplicaciones de la neuropsicología o la psicología, por ejemplo, sino poniendo la lupa a los cursos de acción en la práctica educacional con éxito tal y como la han llevado a cabo los educadores a lo largo del tiempo: reflexionando sobre las causas del éxito y el fracaso real de las acciones educacionales. Ello supone advertir que la calidad racional de la acción pedagógica no vendrá directamente del estudio de la epistemología sino de la calidad racional con la que se reflexione sobre la praxis y la técnica educacional. La epistemología pedagógica sería así un producto racional de la acción educativa racionalmente reconstruida.

De otra parte, hablar en educación de acción mediada simbólicamente debe incluir en su interpretación también la mediación instrumental y la mediación institucional-comunitaria, o lo que es lo mismo, el mediador simbólico no sólo es el lenguaje, pues una inmensa cantidad de procesos interactivos tiene como mediador la corporeidad o sus prolongaciones.

Precisamente por ello, y aunque el concepto de mundo de la vida es pertinente para el análisis sociológico de cualquier categoría de acción, donde resulta máximamente necesario es en el dominio teórico y práctico de la acción comunicativa y educativa. En todas las categorías de acción interviene como ingrediente para construir y justificar el plan de acción; de ahí que se construya el problema sociológico de determinar la medida en que los planes de acción de los sujetos reproducen las condiciones del mundo de la vida e innovan en él; refuerzan con la interacción los vínculos de pertenencia a su grupo de referencia y remueven críticamente las pretensiones de validez del mundo de la vida mediante la reflexión interactiva. Pero en la acción comunicativa el mundo de la vida instaura el proceso fundamental de educación y formación de las personas: «el niño, al participar en interacciones con personas de referencia que actúan competentemente, internaliza las orientaciones valorativas de su grupo social y adquiere capacidades generalizadas de acción.

\subsection{Existencia de bechos y fenómenos educacionales}

Para nosotros el referente del concepto Teoría de la Educación es el producto de la actividad intelectual que pretende reconstruir la estructura de hechos o acontecimientos educativos, de realidades educacionales; interpreta el modo de funcionamiento de los procesos e intenta explicarlos mediante la elaboración de conceptos y proposiciones que representen esas realidades educativas fluyentes y 
fugitivas; pero no se agota el objetivo en la descripción-explicación, sino que también pretende crear el esquema mental desde el que orientar la acción cuando sea posible.

Para que sea, pues, posible la elaboración de esa teoría así concebida se han de dar tres requisitos fundamentales:

a) La existencia de hechos o fenómenos, todos ellos, por sus características, atribuibles a la condición de educacionales.

b) La advertencia de relaciones entre esos fenómenos, lo que permite la reducción de los mismos a categorías, v. gr., enseñanza, evaluación, reforzamiento, socialización...

c) Propuesta de fórmulas o leyes en la que se condense el contenido de lo que se entiende como explicación, v. gr., "si un niño ha alcanzado la fase biológica justa para aprender a hablar y entender, posee también la madurez mental necesaria para aprender a leer a la misma edad y del mismo modo que aprende a hablar".

En el fondo de este planteamiento anidan varios problemas fundamentales. El primero se deriva de la cuestión de si los géneros y las especies existen o no por sí mismos, si existen separados de los objetos sensibles o en estos objetos formando parte de ellos; este problema tiene incidencias no despreciables en lo que por educación deba entenderse. Las posiciones a este respecto son muy extremas: de un lado, se dice, los universales, los conceptos generales son previos a las cosas mismas, aunque no sea sencillo determinar el modo de su existencia; de otro, se entiende que los universales son meras abstracciones o productos conceptuales del entendimiento, obtenidos a partir de la consideración de las cosas; entre estos dos extremos, que vienen a coincidir con las posiciones epistemológicas denominadas idealismo y realismo, se sitúa una gran variedad de posiciones intelectuales.

No entraremos en cuestión tan espinosa. Simplemente indicaremos algunos pensamientos que pogan cierto límite y precisión al valor de cuantas teorías educacionales pudieran formularse. Es muy frecuente dentro del discurso pedagógi$\mathrm{co}$, aludir a un elemento absoluto, ontológicamente anterior al proceso histórico de educar, el cual se presenta como arquetipo e intención del proyecto educativo. Las expresiones "desenvolvimiento armónico", "Configuración", "recto crecimiento", "guía hacia lo mejor", "formar segun la naturaleza", "crecimiento normal" ..., utilizadas por doquier al referirse a la educación, parecen aludir a un elemento canónico extrahistórico, que se convierte en criterio de actuación. Con frecuencia da la impresión de que el fruto de la actividad humana en materia educacional alcanza únicamente la secuencia de acción mediante la cual se persiguen esos ideales. Los ideales mismos poseerían otro origen, diferente al de los conceptos que representan los procesos mediante los cuales se intentan alcanzar. Para nosotros, independientemente de la forma como se justifican las influencias que se promueven o los contenidos que se enseñan, toda esta actividad histórica por la que una generación trasvasa su cultura a otra generación es realidad educacional, hecho educativo. Los criterios mediante los cuales se organiza la acción, se 
valoran sus efectos o se explican los procesos son discurso educativo, producto intelectual, incluso las metas últimas que se proponen a la acción son consideradas como productos del entendimiento humano.

En consecuencia, es un presupuesto ontológico fundamental a toda teoría, y a toda teoría de la educación, la percatación de la existencia de dos tipos de entidades: las que componen la realidad externa a nosotros, en tanto que sujeto que conoce, y los productos que tienen su origen en la propia actividad de conocimiento; los fenómenos que nos aparecen como fenómenos educacionales y la actividad intelectual que culmina en lo que denominamos Teoría de la Educación. Los primeros son objetos que llamaremos reales y los segundos son objeos conceptuales. Estos últimos contienen tres componentes fundamentales: predicados, proposiciones y teorías.

Los primeros, los fenómenos externos, podemos calificarlos de hechos, dado que su existencia es independiente de que alguien los piense; los segundos pasarán a denominarse constructos, porque son producto de la actividad intelectual. La característica más aparente de los hechos - y de los hechos educacionaleses su recurrencia o monotonía, semejanza de propiedades, que permite su agrupamiento en clases. También se atribuye a los hechos del mundo la propiedad de la complejidad o la posibilidad de determinar en ellos elementos o componentes cada vez más elementales o simples, o de considerarlos en sistemas cada vez más amplios (organismos, ecosistemas, sociedades, culturas...).

Otra advertencia fundamental sobre los hechos reales consiste en que todos los hechos, agrupados en sistemas, al vincularse unos a otros producen en el sistema resultante propiedades nuevas o emergentes no incluidas en los componentes elementales. Así, las propiedades de los hechos biológicos no están incluidas en los hechos meramente fisico-químicos, ni las propiedades de los hechos mentales en los hechos biológicos. En consecuencia, se pueden determinar propiedades específicas de los fenómenos educacionales que no sean reductibles a propiedades de los componentes más elementales que los integran.

\section{PRESUPUESTOS GNOSEOLÓGicos}

\subsection{Los productos del pensamiento educacional}

Hemos dicho que, además de los hechos del mundo, exite un segundo bloque de realidades compuesto por los productos de nuestro pensamiento educacional, es decir, construidos por el hombre como ser que tiene la propiedad de concebirlos: los llamaremos constructos u objetos conceptuales. La educación, pues, tiene ese doble aspecto de conjunto de hechos del mundo, en este caso hechos característicos del mundo humano, y construcción conceptual con la que se pretende describirlos y explicar el conjunto de propiedades y relaciones que caracterizan los reiterativos fenómenos que clasificamos como hechos educacionales. En tanto que reproducción conceptual de hechos compuesta, como indicamos, de predicados, proposiciones y teorías, esas construcciones intelectuales pueden ser calificadas de verdaderas o falsas. 
Tan obvias observaciones no parecen ser siempre mantenidas al confeccionar el discurso pedagógico; algunos autores confunden la educación como hecho del mundo con la educación en tanto que descripción intelectual y valoración de aquélla. Los hechos del mundo son o no son, se producen o no se producen, del mismo modo que los procesos de influencia, en general, tienen lugar o no tienen lugar.

\subsection{La educación como proceso vitalmente necesario}

La educación es un hecho necesario que tiene lugar como un elemento más de perpetuación específica y de sobrevivencia. La educación adquiere condición valorativa de buena o mala, adecuada o inadecuada, desde el momento que en el proceso educacional la influencia ejercida y los valores adquiridos por el producto de tal influencia se ponen en relación con los valores proyectados culturalmente en forma de umbrales canónicos, prototipos o como quiera llamárseles — productos intelectuales con función normativa. Tal valoración, es, pues, consecuencia de la proyección intelectual del hombre sobre hechos del mundo, en este caso, hechos del mundo humano.

Pues bien, el discurso educacional, incluso el cultural, contiene en nuestros días prioridades tales como autocomprensión, actividad racional, adecuación moral, formación intelectual... que olvidan y ocultan aquella primera función adaptativa. La reflexión sobre la mente y su funcionamiento aparece hoy como exigencia de la evolución cultural y para cometidos culturales y no como una función propiamente adaptativa, cuando en la evolución lo que se consideró ventajoso fue, ante todo, la intensificación de la atención para los cambios en el entorno a corto plazo que desarrollan funciones mentales. De hecho los primeros pasos de la relación con el entorno que forman la mente, y donde las carencias básicas producen los mayores perjuicios, no están dirigidos racionalmente: junto con la leche materna el niño recoge en la urdimbre de relación afectiva el alimento para su capacidad lingüística, objetiva y personaliza la relación, elabora patrones de comportamiento, crea esquemas interpretativos, identifica su sexo y su grupo... Todos estos procesos de conformación son, en parte, independientes del contexto cultural considerado (tienen lugar en todos los contextos y quedan contextualizados), son necesarios antropológicamente; su inexistencia o anormalidad produce anomalias, pudiendo dejar al individuo en condiciones antropológicas irreconocibles. Estos hechos y procesos educacionales primarios conforman el fundamento de toda ontología y antropología educativa y deberían constituir un punto de referencia ineludible en la reflexión educativa, pues no solamente trasmiten cultura sino que constituyen el fenómeno global de la adaptación sobrevivencial humana, está en juego la condición humana y no meramente la condición cultural.

\subsection{Unidad e integración mental}

El estudio de la mente como problema unitario puede hacer caer en el error de la unidad estructural de la mente, cuando en realidad se encuentra compuesta 
por sistemas diferentes en red y por sistemas paralelos con niveles diferentes de funcionamiento autónomo aunque fuertemente interconectados, lo que obliga a la consideración de los mismos de forma integrada pero también a su consideración particular (emociones, ideas, esquemas) y a la posible trasferencia de patrones de la actividad mental de unas situaciones a otras empleando criterios no precisamente lógicos en todos los casos; son mecanismos que operan frecuentemente bajo el criterio de seguridad y respuesta rápida más que bajo criterios de respuesta racional.

La perspectiva corriente en el análisis de la actividad mental no toma en consideración los centenares de miles de años en los que la evolución la conformó adaptativamente para un mundo totalmente desaparecido y del que no quedan más que aquellas exigencias vitales a cubrir en los nuevos contextos. La afectación más profunda de la actividad mental procede de esta historia adaptativa y no de la historia cultural de los individuos, de las exigencias de aquélla y no de ésta; de ahí la relación equívoca entre el hombre y la cultura, porque no son las exigencias culturales las exigencias primarias, sino las otras; el problema estriba en cómo se satisfacen aquéllas en los contextos que crean éstas. Tal era el sentido hondo del malestar de la cultura de Freud. Las adaptaciones culturales como producto de la formación se someten al principio de que nada aprendido se incorpora a la especie y la facilitación de los procesos primarios serán consecuencia de la estructura que adquieran los contextos en los que la nueva criatura se inserte.

La sintonía entre el cerebro y el mundo ofrece diferencias según la forma de la experiencia, puesto que la adaptación al mundo es primariamente local y no general. Todo indica que el proceso primario de formación de la mente parece ser más bien de cerramiento (construcción de rutinas para diferentes situaciones, mente emplazada) que de apertura, como si el recuerdo de una experiencia en vez de depósito de datos constituyera razonamiento económico para la otra situación (transferencia). El sentido común muestra diariamente que el dilema que un individuo encuentra en una situación novedosa no es de dificultad racional, sino de lagunas de adaptación — de ahí el uso del prejuicio- que difícilmente se remedian mediante argumentos.

Los procesos educacionales tienen un componente de adaptación cultural, pero no suprimen ni siquiera vicariamente las exigencias adaptativas que creó la evolución (mecanismos primarios), porque la selección natural es impersonal, lenta (es historia de poblaciones y no historia de la vida individual) mientras que la educación es personal, rápida (a lo largo de la vida del sujeto) y artificial (en esta cultura y no en otra).

\subsection{Actividad mental y situación}

La situación en la que se encuentra el agente es para éste sólo un fragmento interpretado de un entorno; precisamente se constituye como tal a partir de la percepción de las posibilidades que representa para su plan. A esto perfectamente

(c) Ediciones Universidad de Salamanca

Teor. educ. 8,1996 , pp. 5-42 
puede llamarse "estado de cosas" sobre el que se puede y hasta se debe intervenir, no meramente cabiar impresiones o, incluso, ponerse de acuerdo.

La situación de la acción delimita, por tanto, y fragmenta el mundo, lo recorta en función del asunto o tema (fragmentos" de procesos o de secuencias de acciones con significado para el actor) al que la acción se refiere. El tema o asunto de la acción lo contienen y expresan los intereses y metas de la acción, tanto si se trata de acciones monológicas —en las que el plan de acción es referido a un participante- como si estamos ante accciones sociales dirigidas por normas, acciones de influencia... e incluso en la acción comunicativa. El tema de la acción circunscribe el ámbito de componentes de la situación que, en virtud de las interpretaciones que de ella llevan a cabo los agentes, adquieren relevancia; en función de esos componentes relevantes se elaboran los planes de acción. Así interpretada la situación es como aparecen a los agentes las alternativas de acción; es decir, la gama de metas, de condiciones y de medios para la ejecución de los planes. Dado que la situación de la acción es la situación interpretada, a ella pertenecen todas las restricciones de la acción que en sus relaciones con el mundo aparezcan para el sujeto: las que se originen en la transacción cognitiva con los hechos (lo que cada uno conoce y sabe), las que tienen origen en el sistema de normas percibidas como pertinentes al caso (el criterio moral de cada cual) y las que lo tienen en las vivencias de los sujetos. De acuerdo con ello parece evidente que las limitaciones en la interpretación de la acción se traducen en limitaciones para la acción posible; esta afirmación tiene consecuencias fundamentales en pedagogía.

En la situación de la acción, ya fragmentada y desgajada del mundo por el tema de la misma, los planes de acción se construyen a partir de las interpretaciones de los agentes. Pueden diferenciarse, por lo tanto, dentro de la situación aquellos elementos que, desde la perspectiva de los agentes particulares, son accesibles a la interpretación y aquéllos otros que permanecen inaccesibles; éstos últimos configuran el contexto de la acción o "mundo de la vida" en palabras de J. Habermas. Dentro de este mundo de la vida, en tanto que horizonte de los procesos de las acciones, los temas de la acción desplazan, en cada caso, los fragmentos de ese mundo que adquieren relevancia. El mundo de la vida constituye, pues, un contexto de acción en el que, en función de los temas, se demarca y define un contexto de situación para la acción. No creemos tergiversar el pensamiento de Habermas, si entendemos que el mundo de la vida es el contexto de las situaciones y la situación es el contexto de la acción.

\subsection{La experiencia como saber de fondo en las interpretaciones}

El mundo de la vida penetra en la acción en tanto que trama de "preconcepciones" acumuladas en la cultura de los sujetos, tanto si actúan para conseguir fines, como si el fin de su actividad es el mutuo entendimiento; el autor lo denomina "saber de fondo", aludiendo a la fenomenología de Husserl.

«Es un saber implícito, que no puede exponerse en una multiplicidad finita de proposiciones; es un saber holísticamente estructurado, cuyos elementos remiten unos 
a otros, y es un saber que no está a nuestra disposición en el sentido de que no podemos hacerlo consciente a voluntad ni tampoco podemos ponerlo en duda a voluntad" 6 .

El mundo de la vida en su totalidad no es sabido propiamente porque no es reflexionado ni críticamente interpretado; tan sólo los fragmentos del mundo de la vida que adquieren relevancia en cada situación se transforman en tema de interpretación y en elementos para la elaboración de los planes de acción. El mundo de la vida - aquí sigue Habermas a Heidegger y Gadamer - no es meramente un mundo de objetos, sino también un mundo de símbolos, de normas, de convicciones interpretativas, de habilidades personales, de saberes intuitivos, de recursos de reacción ante urgencias situacionales...: es mundo de hechos y mundo de cultura y mundo de lenguaje en la medida en que, como decía Ortega y Gasset, las palabras son los nichos en los que anidan las ideas. El saber de fondo es el que interconecta en cada situación, por la formación cultural que ha recorrido cada sujeto, el mundo de los objetos, el mundo social y el mundo de las vivencias. Esta es la medida y la forma en la que penetra el mundo de la vida en las interacciones de los sujetos. Al cambiar de plan de acción o al cambiar de tema de conversación o al cambiar de interlocutores, las personas nunca salen del mundo de la vida, como tampoco el mundo de la vida se torna en tema, sino tan sólo aquellos fragmentos del mismo que configuran las posibilidades de acción en cada situación.

\subsection{Diversas formas de racionalidad, diversos criterios de legitimación de la decisión}

Quedan, pues, perfectamente demarcados "dos conceptos de racionalización", dos formas de comportamiento racional7: el de la acción racional respecto a fines (ciencia y tecnología) y el de la racionalización en el marco institucional que "sólo puede realizarse en el medio de la interacción lingüísticamente mediada, consiguiendo que la comunicación se vea libre de restricciones...; (es decir) la discusión pública sin retricciones y sin coacciones... (como las construidas por la razón política)...»8. La actividad de razón aparece en el mundo humano dentro de una gama que va desde la reflexión autónoma denominada de sentido común hasta los productos del conocimiento científico. Algunos consideran que el único ámbito de la racionalidad es el polo cintífico o su equivalente en el campo de la acción social, la racionalización, la cual se entiende como el proceso por el que se amplían y aumentan los ámbitos sociales que

6. Habermas, J. (1982): Observaciones sobre el concepto de acción comunicativan, en HaBermas, J.: La teoría de la acción comunicativa: complementos y estudios previos. Cátedra, Madrid, p. 495.

7. IDEM (1986): Ciencia y técnica como ideología. Editorial Tecnos, Madrid, p. 106.

8. Tal modo de configurar la "formación de la voluntad colectiva"... "no conduce por si a un mejor funcionamiento de los sistemas sociales; pero dotaría a los miembros de la sociedad de oportunidades de una emancipación más amplia y de una progresiva emancipación», IBIDEM, p. 107. 
quedan sometidos a los criterios de la decisión racional; la industrialización progresiva del trabajo social y penetración de la acción instrumental, de la mediación instrumental en otros ámbitos de la vida social y la interpretación de la planificación como el orden superior del sistema de acción. Además del proceso de investigación que se propone explicar el suceso, también la razón se emplea en la identificación y la elección de alternativas, en la selección de los medios y en la decisión del curso de acción posible.

Tal racionalización de la vida social es la consecuencia de la encarnación de la ciencia y la técnica en las instituciones sociales, de la absorción de la evolución del sistema social en el interior del progreso científico y técnico, como si fuese necesario o por lo menos más valioso que el sistema de la ciencia y la técnica se constituya en la vertebración del sistema social, cosa que nunca aconteció en la historia humana. La consecuencia inmediata es la pérdida de valor de las cosmovisiones colectivas como orientadoras de la acción, la desaparición de las legitimaciones sociales tradicionales, el menosprecio de la tradición cultural en su conjunto...; tal es el significado sociológico del concepto de "secularización" del pensamiento y por ello es imprescindible la teoría crítica que desenmascare y diseccione el conocimiento y el interés. El postulado fundamental de la teoría crítica es el de que la absorción progresiva del sistema social en el sistema científico tecnológico no se deriva de criterios de racionalidad sino que también se entreveran intereses menos legitimables.

Muchos son los que afirman que tiene la humanidad tecnología suficiente para garantizar un nivel de vida razonable a toda la comunidad; pero el proceso hacia ese objetivo pasa por resolver un conflicto que Stanislav Grof? define como "desequilibrio entre el precipitado desarrollo intelectual y la madurez emocional de la raza humana, una evolución desproporcinada del neocortex en relación con las partes arcaicas del cerebro". El planteamiento de las metas de la educación debe incluir sistemáticamente el desarrollo emocional, junto al intelectual y al ético; la afectividad ha de despolarizarse de la identificación con el Yo y promover experiencias de identificación transpersonal. Digamos que el problema intelectual que se propone es el de la armonización entre los procesos primarios y arcaicos de la educación - primitivos-y los procesos institucionales. La solución a los problemas de la civilización actual no se persigue lógicamente, buscando únicamente nuevos modelos y complejidades al desarrollo tecnológico, sino procurando dar pasos serios en la evolución de la conciencia; tan sólo entonces el desarrollo tecnológico expresará auténticamente su condición de mediación técnica. En tal evolución muchos datos los proporcionan los estados de cosas afectivos y emocionales de la colectividad y su tratamiento en la cultura. La cultura actual no incluye para muchos miedo al agotamiento de los recursos, no padece el naufragio del desarrollo en pueblos enteros, representa y muestra estéticamente la inmadurez psicológica sin comprenderla, da vueltas comprensivas alrededor de patrones neuróticos sin crear condiciones para que no aparezcan, prefiere desarrollar tecnologías terapéuticas. Digamos que un

9. GROF, E. y OTROS (1994): La evolución de la conciencia. Ed. Kairós, Barcelona. 
tema de estudio soslayado en la Teoría de la Educación es el del valor del sentimiento para los objetivos generales de la cultura y el de justificar que se tome más sistemáticamente en consideración en el análisis de la acción pedagógica el papel de la emoción, la sensibilidad, la afectividad, para que intervengan como componentes explícitos en las propuestas, en los diseños y en la construcción de condiciones en vistas a la formación.

\subsection{Otros ojos del conocimiento: poesia, arte, sentimiento}

Cuando se toma este punto de vista hemos observado, personalmente y en la experiencia de otros autores, la inmediata recuperación de dos valores culturales, otros modos de actividad mental distintos a los considerados prototípicamente racionales, pero que, según la expresión de Ken Wilder, también son "ojos del conocimiento" 10 : de un lado, la poesía y las artes y, de otro, el aspecto de investigación pragmática de la experiencia que contienen los aspectos no dogmáticos de las religiones, aquél que propiamente tiene el tono y la forma de una propuesta de educación de la sensibilidad y de la conciencia.

De la poesía puede ser un testimonio lo que expresa Jerome Bruner con el subtítulo "Los actos de la imaginación que dan sentido a la experiencia"11. El concepto de poesía no se toma aquí en tanto que actividad artística sometida a cánones expresivos, sino en lo que tiene de actividad original y que Octavio Paz define como "el testimonio de los sentidos"12; el testimonio poético revela "Otro mundo... (en el que) los sentidos, sin perder sus poderes, se convierten en servidores de la imaginación y nos hacen oir lo inaudito y ver lo imperceptible; todo ese mundo experimental ordinario en el que el hombre toma decisiones y se juega la vida, se compromete o descompromete, incluyendo en el argumento lo que coloquialmente se designa como el lenguaje del corazón ${ }^{13}$. Con esa declaración recogemos en gran medida la forma más directa en la que nos percibimos y el resumen del mundo y la vida que elaboramos como el resultado más inmediato de nuestras propias aspiraciones-deseos. Es como detenerse un instante para tomar en consideración la expresión coloquial "hablo con el corazón en la mano", respecto a lo cual el pensamiento es una consecuencia mucho más indirecta de la experiencia inmediata.

El mundo, en tanto que etodiversidad que se ofrece a la interacción (tanto en el sentido de diversidad de hábitos-costumbres, como en el sentido de formas de

10. WILDER, K. (1994): Los tres ojos del conocimiento. Ed. Kairós, Barcelona.

11. Bruner, J. (1988): Realidad mental y mundos posibles. Ed. Gedisa, Barcelona. El autor habla de "dos modalidades de pensamiento: la paradigmática lógico-científica y la aplicación imaginativa de la modalidad narrativa; una y otra tienen puntos en los que se habla de cosas diferentes. La segunda se ocupa de las "vicisitudes de la intención", no en el sentido de la justificación de la acción sino más bien en el de la in-tensión, de la trama de la conducta y del estado del Self que no es consecuencia de la deducción; por eso no se acomodan a la argumentación paradigmática sino a la argumentación del relato y el poema.

12. PAZ, O. (1993): La llama doble. Amor y erotismo. Ed. Seix Barral, Barcelona, p. 9.

13. ViscotT, D. (1988): El lenguaje de los sentimientos. Ed. Urano-Emecé, Barcelona, p. 19 y ss. 
ser y formas de vida) es tan complejo e inédito en cada instante que no podemos depender en exclusiva, ni de hecho dependemos, de nuestra capacidad intelectual-lógica para evaluar e integrar nuestras percepciones. La sensibilidad, emocionalidad, afectividad representan atajos, frente a los rodeos lógicos, en toda nuestra actividad mental. En la vida ordinaria, con más frecuencia de la que seríamos capaces de admitir, los sentimientos evalúan la realidad. La gran lección del Psicoanálisis, todavía no invalidada, es que el camino hacia la armonía personal -el equilibrio entre deseos y realidad - no se construye entre la gente tanto con materiales de comprensión racional cuanto de refinamiento en la interpretación de sus impulsos y sentimientos. Todas las manifestaciones artísticas aparecen en tanto que celebración-plasmación de sentimientos. El sentimiento es el primero en prestar atención a la realidad, el primero en la historia antropológica y el primero en la historia personal; incluso, en muchas ocasiones puntuales, no solamente suele ser el primero sino también el último, y en otras muchas termina por ser el único.

De lo segundo -el componente no dogmático de las religiones-, es un ejemplo el libro De cuerpo presente ${ }^{14}$, donde se recompone la relación del hombre con el mundo y sus consecuencias epistemológicas tomando en consideración una de ellas: la reflexión budista; el análisis se puede extender en esta perspectiva a otras formas de religión. Para nosotros, aquí, lo más importante es tomar conciencia de que lo que se ofrece reflexivamente sobre la experiencia, incluso en el análisis fenomenológico, suele consistir en ofrecer un "proyecto de reflexión teórica sobre la experiencia" abstracta e incorpórea; si la vida se instituye en los individuos por otros caminos, debe caber igualmente una reflexión "corpórea" o desde el punto espontáneo en el que se funden habitualmente la mente y la corporeidad, punto desde el que todos afirman sus raíces o sus desarraigos personales, culturales y sociales.

Jack Kornfield ${ }^{15}$ lleva a cabo un planteamiento en este sentido y en ese contexto respecto a la responsabilidad social en el momento actual de nuestro mundo. Estos ejercicios de análisis pragmáticos de la experiencia humana se pueden llevar a cabo desde los contextos más dispares en origen pero concordantes en cuanto a la perspectiva: lo que algunos denominan planteamientos de antropología transpersonal. Hoy, comportarse globalmente de manera educada no puede expresarse únicamente en términos de autonomía personal, de Yo realizado, de individuo capacitado, de calidad de acción definida por caracteres de sus consecuencias inmediatas; el contexto es global, el medio informacional es societario, el objeto de la consideración que se impone incluye a los individuos en el marco de la "necesidad de la condición humana"; por lo mismo, la calidad y el valor de

14. VARELA, F. J. y OTROS (1992): De cuerpo presente. Las ciencias cognitivas y la experiencia bumana. Ed. Gedisa, Barcelona.

15. Kornfield, J. (1993): "La vía budista y la responsabilidad social", en Grof, E. y otros: op. cit., pp. 192 y ss. Señala el autor que es esencial, dentro del análisis de la experiencia que conduce según el budismo a la liberación personal, distinguir y comprender el significado de las cualidades fundamentales de la práctica espiritual: amor, compasión, alegría empática y ecuanimidad, términos que parecen extractados de un tratado sobr emociones primarias. 
una configuración cultural (científica, técnica o ideológica) debe estimarse en perspectiva de humanidad, de consecuencias ecológicas actuales o de estimación a largo plazo, de contenido de felicidad personal y colectiva, de prevención de la enfermedad emocional y de fortalecimiento de la conciencia. Al menos en Occidente esto supone recomponer algunas urdimbres mentales, en concreto el papel de la corporeidad y de manera muy específica tomar en mejor consideración el campo de la emocionalidad, la sensibilidad apreciativa, el estrato de la emocionalidad en el comportamiento de todo orden.

\subsection{La perspectiva global, la perspectiva sistémica, gnoseología de la complejidad}

Macroscopio es el título de una obra de Joël de Rosnay ${ }^{16}$ publicada en 1975; ya en ese momento su reflexión pretende acometer la percepción de lo infinitamente complejo. La palabra complejidad es una de las que más se traen a colación en el lenguaje coloquial cuando se afrontan los problemas sociales y culturales, y es dentro de esta perspectiva intuitiva desde donde toma posición el educador, entre otros profesionales, para su toma de decisiones. El macroscopio es un instrumento simbólico que representa "una nueva manera de ver, de comprender y de actuar"; así como el microscopio posibilita la visión de lo demasiado pequeño o el telescopio lo hace respecto de lo demasiado lejano, aquél media en la comprensión de lo demasiado complejo; esta perspectiva se corresponde con la ontología anteriormente descrita para los fenómenos educativos ${ }^{17}$.

La metodología más habitual en el conocimiento ha sido la de aislar, descomponer la realidad; en esta otra perspectiva predomina la intención de encuadrar $^{18}$ para ver totalidades, reunir e integrar para mejor comprender, situarse ${ }^{19}$ para actuar mejor.

Entre otros indicios de ese cambio de mentalidad reseñada, quizás el más evidente sea la generalización de toda una gama de conceptos aplicados a muchos ámbitos de la realidad: energía, información, utilización y circulación de la energía y la información, flujos y ciclos, redes de comunicación, catalizadores y agentes de transformación, equilibrios, desequilibrios..., pero, sobre todo, la noción misma de sistema. Antes que contenido de conocimiento, el concepto arrastra una metodología para acceder al conocimiento, una perspectiva para considerar la realidad y no meramente contemplativa, sino como auxiliar para la toma de decisiones y para el diseño de acciones más eficaces; eficacia no exclusivamente valorada en función de una variable particular sino del estado general de sistema y de consecuencias globales a medio y largo plazo. De ahí que los modelos y metáforas más utilizadas fueran reloj, máquina, organismo, ordenador... El crecimiento del plan de investigación a través de la metáfora fue claro en los años 40, cuan-

16. Rosnay, J. DE (1975): Le macroscope. Vers une vision globale. Ed. du Seuil, Paris.

17. William-Lapierre, J. (1992): L'analyse de systèmes. L'application aux sciences sociales. Ed. Labor, Paris.

18. Goffmann, I. (1991): Les cadres de l'experience. Ed. Minuit, Paris.

19. Habermas, J. (1987): Teoria y práxis. Estudios de filosofía social. Ed. Tecnos, Madrid. 
do se toma el modelo orgánico para el diseño de herramientas con feed back y objetivos de acción; en los 50 es la máquina la que proporciona perspectiva para comprender la memoria, los fenómenos adaptativos, el funcionamiento de la célula (biónica), la inteligencia (inteligencia artificial), ...los mecanismos del comportamiento; en los años 60 con la cibernética se produce una transferencia de modelos hacia la empresa, la sociedad y la ecología.

Ya hemos visto que en la noción de sistema queda incluida la totalidad de elementos integrados y la noción de entorno. Pues bien, en correspondencia con estos dos conceptos ontológicos se incluyen los de estado y situación; ello no quiere decir que en esta perspectiva se desprecie el pormenor, si bien es cierto que se hace siempre bajo la óptica de la integración; y por este camino se descubre el bucle de información circular o retroacción negativa imprescindible para corregir un curso de acción. Es difícil sustraerse a pensar que en este encuadre de circularidad que atiende el indicio en el proceso para corregir la acción en curso se encuentra el humus para su adaptación al comportamiento humano y a los procesos de influencia, hoy nombrados como proceso de reflexión en la acción.

Ahora bien, si la perspectiva sistémica se reduce a una teoría, aunque sea la Teoría General de Sistemas, o a una tecnología, aunque sea la cibernética, volvemos a caer en las ciencias humanas en reduccionismos mecanicistas, porque el hombre reflexivo sobre la praxis quedaría modelizado como un servomecanismo ${ }^{20}$ y el funcionamiento mental se representará bajo el criterio que proporciona la metáfora del ordenador. Sin embargo el concepto de circularidad es mucho más amplio y englobante, se trata de una categoría de causalidad jerárquicamente de orden superior en su significado a sus concreciones en campos teóricos particulares, por más que descubre armonía y autonomía entre los componentes del mundo de la vida. No se olvide tampoco que es la voluntad de encontrar modos de comprensión de la complejidad, de la multitud de elementos y de datos proporcionados por sistemas dinámicos -en permanente situación de perturbación o cambio-, en definitiva, la comprensión de la incertidumbre, la que ha producido el desarrollo del cálculo de probabilidades, las teorías del caos...

El concepto de meta aquí implícito es polisémico en función del sistema considerado. En la máquina es puesto por el hombre en la estructura del diseño; en la célula no traduce proyecto de ninguna clase y en el ecosistema consiste en el mantenimiento de su propio equilibrio dinámico. En un sistema pedagógico se trata de finalidades de carácter general o de propósitos de las agencias educacionales. Dicho en otras palabras, la definición de sistema necesita ser interpretada, es decir, tendremos que definir el contexto en el que empleamos esta noción para que se cree el significado que se atribuya a cada uno de los componentes de la definición; de ahí el error de emplear los términos de la Cibernética o de la Teoría

20. Algunas veces, criticando un planteamientos tecnológico con causalidad lineal, variable a variable, se critica también todo criterio para acción racional aludiendo a que Wiener trabajaba para el ejército, junto a $\mathrm{H}$. Bigelow, en la construcción de un cañón antiaéreo; y Forrester fue encargado por Air Force para conjuntar radar y ordenadores. 
General de Sistemas sin especificar las restricciones propias del contexto educacional en el que se están empleando.

De igual manera, la noción de complejidad ${ }^{21}$ requiere la interpretación y explicación de la variedad de los componentes considerados y de las funciones que se han de tomar en consideración, tanto en el caso de que se considere un organismo, una máquina o un subsistema comportamental humano. Los componentes (categorías de elementos, familias o poblaciones...) en la noción de sistema se relacionan (variedad en las relaciones) y se organizan jerárquicamente (variedades cualitativas de jerarquía); los efectos en un dominio del sistema no covarían de manera constante con otros dominios (variación no lineal); la comunicación entre las partes, contenido de una relación de información, no es tampoco lineal sino en red; entre los componentes del sistema tienen lugar flujos de información (no es necesariamente un concepto cuantitativo); en la jerarquía funcional existen centros de decisión que transforman la información en decisiones de acción, control del flujo de información y de velocidad de circulación de la misma; la circulación de tal información puede tener la característica de una retroacción positiva (la que explica la dinámica de cambio) o de una retroacción negativa (la que explica la regulación y la estabilidad del sistema, autorrestaura o autoconserva). La retroacción negativa reenvía al pasado del sistema, el bucle positivo acrecienta la divergencia, la expansión, la explosión, lo insólito en el sistema. El bucle positivo llevaría al cambio y a la destrucción del sistema, el negativo al comportamiento adaptativo o finalista del sistema ${ }^{22}$.

La variabilidad en el sistema puede, pues, conectarse tanto a la noción de flujo como a la noción de estado; la variable de flujo contiene como marco de referencia dos momentos, la de estado (en valor cuantitativo o cualitativo) se concreta en un momento dado. Para no quedarnos en nociones, en el contexto pedagógico las variables sobre las que reflexiona el profesor duante el proceso educativo son de flujo (proceso) y las que evalúa al final de un proyecto son de estado. La perspectiva sistémica se concreta en interacciones, se apoya en percepciones globales, modifica familias de variables, integra en la interpretación el tiempo y la irreversibildad; la evaluación del proceso dinámico se establece en comparación con el modelo proyectado, conduce a la acción por objetivo-proyecto e implica un conocimiento reflexivo de las finalidades junto a los pormenores de fluencia en los procesos. El comportamiento de los sistemas en esta perspectiva implica la noción de imprevisibilidad 23 , irreproductibilidad e irreversibilidad. Todo lo anterior constituye parte, someramente enunciada, del aparato conceptual con el que se describen sistemas complejos.

En consecuencia, al criticar una aproximación tecnológica (proyectos de acción) en contextos pedagógicos, debiéramos distinguir previamente entre los conceptos de acción y tecnología dentro del modelo racional de la ciencia clásica

21. Morín, E. (1995): Introducción al pensamiento complejo. Ed. Gedisa, Barcelona.

22. ROSNAY, J. DE (1995): L'bomme symbiotique. Regards sur le troisième millénaire. Ed. Seuil, París.

23. Moles, A. (1995): Les sciences de l'imprécis. Editions su Seuil, Paris. 
y modelos de racionalidad derivados de la toma en consideración de sistemas dinámicos. Todos los elementos del aparato conceptual anteriormente aludidos, una vez explicitado el contexto (el contexto es el que crea el significado), delimitan la validez de interpretación y la emergencia que lo caracteriza. Es frecuente, encontrar grafos de flujo, nombrados como modelos de acción, por ejemplo en un sistema didáctico, al mismo tiempo que se pone en entredicho la que se denomina interpretación técnica, cuando la modelización es una de las consecuencias racionales de la perspectiva sistémica, la consecuencia de la imprevisibilidad del sistema real, de su irreversibilidad y de su irrepetibilidad, junto a las posibilidades representacionales que permiten los macroscopios. Quien opera conceptualmente con una modelización está operando en perspectiva sistémica; en pedagogía la mayor parte de los modelos que se encuentran en los autores son modelos conceptuales, construidos con categorías de elementos, sin prejuzgar ni siquiera su posible representación matemática, lo que no implicaría necesariamente la consideración cuantitativa de los dominios de las familias de variables; por supuesto, que ni siquiera se plantea la tarea de si es posible simular el modelo mediante computación.

En el proceso de educación siempre se ha considerado esencial la propuesta de meta o valor, aunque sea valor o meta única y común; el flujo permanente de acciones-informaciones-energía (influencias) supone y crea un sistema de realimentación positiva dentro del cual permanentemente crece el in-flujo; globalmente considerado este dinamismo lleva, la experiencia lo muestra, al crecimiento de la diversidad; el bucle de retroalimentación positiva es un generador aleatorio de diversidad, porque amplifica las posibilidades de elección, acentúa la diversidad, genera complejidad...; es la ley de Ross Ashby (Ley del requisito de variedad). Dicha ley quiere indicar que no es posible el control de un sistema complejo si no es mediante un sistema regulador tan complejo como el propio sistema dinámico. Este plantemiento obliga a reconsiderar las nociones de proyecto pedagógico, de control de procesos, de evaluación... etc. Lo que propiamente lleva a cabo un educador, un profesor es un control global del proceso de influencia que él genera y una comprobación global del aleatorio comportamiento del educando en función de la referencia global de la meta que se propone. Por el mismo motivo por el que la influencia no reproduce, sino que acrecienta la variedad, es por lo que respecto al contexto de acción proyectado es tan alto el conjunto de los efectos o comportamientos imprevistos ${ }^{24}$.

\subsection{La educación como proyecto}

La educación tiene dos dimensiones acordes con lo dicho anteriormente: los estados del sistema sobre los que se interviene y la forma proyectada en la que

24. Dada la actualidad de estos plantamiento son bastantes los que manifiestan sus reservas, sus críticas e incluso sus menosprecio. Horgan, J. (1995): "De la complejidad a la perplejidad", en Investigación y ciencia, 71 ss. 
dispone secuencialmente la acción (proyecto de acción) en el espacio, en el tiempo y en la dimensión social. Tal proyecto no es un hecho del mundo, una variable del sistema en el que se interviene - sistema educado-, sino un producto intelectual, un proyecto de educación que, tras el análisis crítico respecto al contenido de sus proposiciones, resulta plausible o no plausible, adecuado o inadecuado, pertinente o impertinente, justo o injusto. Parece más apropiado decir esto que verdadero o falso, dado que este calificativo no se predica con propiedad de las acciones sino de las proposiciones.

A veces, en la crítica sociológica se confunden los anteriores niveles de análisis, por ejemplo, Carlos Lerena ${ }^{25}$ desgrana las siguientes afirmaciones: "la palabra educación no dice la verdad", "con el término educación no estamos ante un concepto, sino ante un precepto", "lo que designa la palabra educación es una determinada jurisdicción de poder", "el falso concepto educación es el bello precepto que permite justificar todo", "la educación es el nuevo nombre que toman las más sutiles operaciones de dominación", "educación, nombre de una celestial, naturalista y liberadora estratagema"; pero un poco más adelante declara que lo que pretende en la obra que estamos citando es construir una crítica de la "representación ideológica de la educación", lo que significa que incidirá en el nivel de la educación como proyecto. Tal dimensión no agota la posiblidad de producción intelectual sobre el fenómeno educativo, dado que cabe, igualmente, la representación conceptual de lo que la educación tiene de proceso; aquí la significación es ontológica y no meramente ideológica.

\section{CRITERIOS DE DEMARCACIÓN EN LA ACTIVIDAD INTELECTUAL}

\subsection{Hecho e interpretación, acción y proyecto}

Hay hechos en el mundo y dentro de ellos hay hechos educacionales; tenemos conocimientos del mundo y conocimiento sobre los fenómenos educativos. Los productos intelectuales son también hechos psíquicos cuya naturaleza estudiará la psicofisiología y la psicología pero, al mismo tiempo, son signo y representación de hechos del mundo, incluidos los acontecimientos humanos. Bajo esta segunda perspectiva, los productos intelectuales "tienen propiedades diferentes e independientes de las propiedades de las cosas que esos constructos representan o a las que esos constructos se refieren" 26 .

Cuando hablamos de acontecimientos negativos, por ejemplo, «educación negativa" (Rousseau), nos hemos introducido en el mundo no de los hechos, sino de las convenciones y valoraciones humanas; la negación solamente tiene sentido en el "mundo" de los constructos intelectuales; la educación negativa supone la existencia de una "teoría" de la educación que le da sentido. La acción negativa

25. LERENA, C. (1983): Reprimir y Liberar. Crítica sociológica de la educación y de la cultura contemporáneas. Akal, Madrid.

26. Quintanilla, M. A. (1981): Fundamentos de lógica y teoría de la ciencia. Ed. Universidad de Salamanca, Salamanca. 
solamente tiene sentido si existe una jerarquía de valor y un juicio de valor; la negatividad se adquiere sólo dentro de la estructura teórica del valor en que la acción es comprendida: la educación negativa es un modo de educación y de intervención pedagógica.

Dado que respecto a los hechos del mundo las construcciones intelectuales tienen carácter de representación, entre el constructo y los hechos existirá referencia, mayor o menor adecuación, pero nunca identidad. De ahí que nunca el conocimiento será definitivo; siempre será posible el progreso. Tal afirmación, en principio, parece una limitación, pero en definitiva es el testimonio de la capacidad ilimitada de conocimiento y progreso intelectual. Y es la razón última que justifica la existencia del método o camino por el que los hombres alcanzan y garantizan el perfeccionamiento del conocer y de la actividad crítica mediante la cual ese conocimiento se perfecciona.

\subsection{Unidad de proceso y pluralidad de perspectiva}

Si unimos la complejidad de los hechos y la relativa adecuación de los constructos intelectuales que los representan, llegamos a la conclusión de la pluralidad de puntos de vista o perspectivas posibles desde las que los hechos pueden ser representados; queda justificada la existencia de formas plurales de actividad intelectual y hasta la pluralidad de ciencias. Así, un mismo conjunto de fenómenos clasificados como fenómenos educacionales puede ser analizado desde puntos de vista diferentes: podemos obtener información sobre los mismos desde teorías distintas que aplican a la experiencia formas de actividad mental diferentes, lo que plantea el problema de los criterios de demarcación del conocimiento. El hecho de que se puedan construir enunciados, obtener información, sobre temas y problemas educativos desde campos científicos muy diferentes no justifica lo que algunos proponen: Pedagogía para lo que se cultiva entre pedagogos y Ciencias de la Educación para lo demás; la especie de planta cultivada no depende del campo ni del procedimiento de cultivo. Pedagogía y Ciencias de la Educación son formas diferentes de nombrar que reflejan perspectivas diferentes.

Es fácil comprobar que el tema educacional teje la vida diaria y ocupa en cada momento buena parte de nuestras preocupaciones. Las intervenciones educacionales forman parte del tejido de acción habitual de padres, profesores, especialistas, políticos, administradores... Tales intervenciones, como es habitual en el hombre, tienen lugar dirigidas por propósitos, orientadas a proyectos o justificadas con razones. Los propósitos, los proyectos y las razones forman parte de la componente cognitiva de la acción humana. La necesidad de esos propósitos, proyectos y razones en todo educador implica que, en todos ellos, casi en todo hombre, exista un sistema o conjunto de pensamientos, más o menos organizado, en el que se racionalizan las acciones que se ejecutan, componiendo su propia "teoría" sobre la educación; en ella se encuentran actuacional y personalmente seguros. Por lo general, esa "teoría" de la educación está conectada con las componentes intelectuales con las que todo hombre justifica e interpreta la propia visión del mundo, 
su misión social y sus objetivos vitales. De ahí, las resistencias a toda revisión crítica de los planteamientos educacionales, ya que supone introducir crisis e inseguridad en los fundamentos que amparan las actitudes personales ante la vida.

Todos, pues, tenemos "teoría" sobre la educación. Demarcar el conocimiento significa introducir criterios que permitan distinguir los contenidos de pensamiento según los criterios de racionalidad con los que se construyen o han sido construidos.

\subsection{Criterios de demarcación epistemológico}

El primer criterio de demarcación lo llamamos epistemológico porque intenta deslindar el conocimiento producido con método científico del que no ha sido así producido: deslinda entre ciencia y no ciencia. Este criterio lo instituye el concepto de ciencia comunmente aceptado por la colectividad de científicos. El fruto de la introducción de tal criterio consiste en la demarcación entre la "teoría" educacional que conforma y anima el pensamiento ordinario y el resultado de la aplicación del método científico al tratamiento cognoscitivo de los fenómenos educacionales. El corpus de conocimientos que así se produzca lo llamamos Pedagogía o Ciencia de la Educación. Pero también es quehacer del criterio epistemológico caracterizar otras formas de pensamiento, v. gr., la ideología, en tanto que también es inspiradora de acción. La actividad intelectual no queda reducida al modo de hacer del pensamiento científico ni los hombres pueden esperar a producir teorías científicas para tomar decisiones. Aunque sólo el pensamiento científico incluye normas para validar sus propias proposiciones, la mayor parte de la acción educativa se rige por lo que hemos llamado "conocimiento ordinario".

Formando parte del conocimiento ordinario está el pensamiento mito-poético, las generalizaciones que se obtienen de la experiencia, las reglas técnicas que se infieren de la actividad práctica; tales elementos protocientíficos son útiles para orientar la acción, a veces son los únicos disponibles. Están garantizados en sus efectos útiles, pero, a veces, la componente científica más valiosa que contienen se reduce a las preguntas que sugieren. También hay que advertir que el conocimiento ordinario se compone, igualmente, de la generalización del conocimiento más depurado en un momento histórico determinado.

El criterio de demarcación epistemológica distingue, pues, entre ciencia y no ciencia en la educación. Ahora bien, formando parte de una ciencia está también un conjunto de problemas que se tipifican como los propios de ámbitos específicos de la realidad.

\subsection{Criterio de demarcación ontológico}

Nosotros lo llamaríamos criterio de demarcación ontológico. La principal división que este criterio establece es la existente entre el ámbito de las ciencias formales y el ámbito de las ciencias factuales; y dentro de las ciencias factuales, la tricotomía existente entre fenómenos físicos, biológicos y mentales. Estos ámbitos

(C) Ediciones Universidad de Salamanca

Teor. educ. 8 , 1996, pp. 5-42 
se encuentran entre sí conectados, ya que las ciencias formales proporcionan estructuras y modelos para su uso en la explicación dentro de las ciencias factuales: la ciencia factual proporciona problemas a partir de los cuales aumentar el poder de análisis de la ciencia formal, y dentro de los problemas factuales ni que decir tiene que existe conexión entre los fenómenos, físicos, biológicos y mentales, aunque no puedan reducirse sus propiedades. El ámbito ontológico de los problemas educacionales cae fundamentalmente dentro de los problemas mentales siendo la Ciencia de la Educación una ciencia claramente factual, recae sobre procesos y acontecimientos, trabaja sobre relaciones entre personas y grupos y sobre el significado de las interaciones.

\subsection{Criterio de demarcación pragmática o económica}

Dentro del conjunto de los problemas de un ámbito determinado se introducen criterios por los que gremios científicos se reparten la ocupación y se van subdividiendo las especializaciones. A veces, la demarcación aquí obedece a razones originadas en las propias teorías científicas y su ámbito de explicación y aplicación; pero, en otras, que un gremio científico se ocupe de un tipo determinado de problemas y no de otro no obedece más que a razones de tipo histórico y, en otras ocasiones, administrativas e institucionales. Por estos motivos, a este criterio lo llamamos criterio de demarcación económica.

Por este criterio la Ciencia de la educación intenta, no sin dificultad, encontrar el reconocimiento de otros gremios para la ocupación de un tipo determinado de problemas y la sanción social respecto a la prestación de un tipo determinado de servicios técnicos. Incluso por este criterio es como, en definitiva, se sanciona la distribución de disciplinas en los planes académicos.

A este respecto es frecuente encontrarse con la observación de que la llamada Ciencia de la Educación se disuelve en sectores científicos de aplicación que han sido producidos por otras ciencias y otros gremios científicos. Así se advierte que los "Fundamentos Biológicos de la Educación", metodológica y ontológicamente son problemas biológicos; la "Sociología de la Educación", metodológicamente, nos refiere a la Sociología; la "Historia de la Educación", a la Historia... ¿Que queda como área específica de la Ciencia de la Educación?

Las causas de tal dificultad se originan en dos motivos, uno epistemológico y otro socio-científico. El primero estriba en que la ciencia clásica nos tenía habituados a la perspectiva analítica de resolución del todo en sus componentes y de búsqueda de causalidad lineal y unidireccional como categoría básica. Con los instrumentos de una sola ciencia se hace imposible el análisis globalizado de un fenómeno tan multivariado como el fenómeno educacional. Ya desde el nacimiento científico institucional de la Pedagogía como ciencia, al menos así lo consideran los propios pedagogos, Herbart hacía depender la fundamentación o la génesis de las proposiciones pedagógicas de dos fuentes distintas, metodológicamente heterogéneas: la Ética y la Psicología. En cualqueir caso, se pretendía construir la Pedagogía como ciencia organizada deductivamente; posteriormente, hipo- 
tético-deductivamente; pero siempre de manera unidireccional y sistemática. Hoy parece claro que no es posible agotar semánticamente el objeto educación si no es con acercamientos polifacéticos.

En segundo lugar, el problema intelectual más grave de la Pedagogía está referido no propiamente al ámbito de las explicaciones, sino al de la toma de decisiones. Hoy no son institucionalmente infrecuentes los equipos multidisciplinares en el estudio sistemático de sistemas complejos. Estudiar la educación supone realizar un corte transversal en el fenómeno humano e implicar en su estudio subconjuntos de especialidades muy distantes. Incluso a pesar de ese esfuerzo seguirán muchos problemas sin resolver y muchas preguntas sin contestar; no obstante, los hombres se educarán todos a todos tomando como fondo el mundo.

La multidisciplinariedad, en lugar de aludir a disolución epistémica, suena hoy más bien a perspectivas de modernidad en cuanto a la tipología del acercamiento problemático; ahora bien, que por este camino un gremio determinado "le coma el terreno a otro" es cuestión de poder y capacidad del gremio, no una consecuencia epistemológica.

El segundo motivo por el que se aludía a la disolución de la Pedagogía lo nominábamos socio-científico. La desvalorización del pensamiento pedagógico y el prestigio limitado de las ocupaciones educativas salpica incluso a los científicos que se implican en el estudio de tal fenómeno. Preferirán vivir cada uno en sus gremios tradicionales (sociólogos, psicólogos, historiadores...), y desde sus propios cenobios iluminar el fenómeno educacional. Tal situación no ha producido, hasta ahora, nada más que hipertrofias de perspectivas que son la consecuencia del real distanciamiento del fenómeno dentro del cual el científico no queda implicado más que en la lejanía del dato, cuando el meollo de la cuestión se anidaba en la toma de decisiones. Parece que los científicos rehuyen ser identificados como especialistas de tiempo completo de fenómeno educacional, cuando tienen oportunidad de complicarse con los destinos de la humanidad, de la sociedad en general, la economía, la vida, la salud...

\section{Caracterización ePistemológica de la Pedagogía}

\subsection{Descripción de la Pedagogía en perspectiva epistemológica}

La Pedagogía no podría ser considerada nunca como una ciencia formal porque no "inventa su objeton, ya que existen en la realidad procesos y hechos clasificados como educativos o componentes reales del campo de referencia del concepto educación; la Pedagogía ha de ser necesariamente una ciencia fáctica o factual. Por lo mismo, mientras el método de comprobación de los enunciados de la ciencia formal es exclusivamente lógico, en las ciencias factuales, y por lo tanto en Pedagogía, se necesita además de la observación, el experimento para la confirmación de sus conjeturas. La demostración de un teorema es una deducción: la coherencia entre un enunciado dado y un sistema de ideas admitido previamente. El teorema alcanza una verdad relativa al sistema teórico en que cada enunciado se desenvuelve y, dado que se construye con términos abstractos no inter- 
pretados, se desarrolla sin preocuparse por la cuestión de la verdad, solamente garantizando las inferencias correctas. Los enunciados matemáticos no son ni verdaderos ni falsos, v. gr., $x-1=0$; solamente será verdadero o falso si se interpreta $x$ como $=1$, ya que de lo contrario es una fórmula vacía. Al interpretarlo tienen una sola solución; en cambio $x-y=1$ permite infinitas interpretaciones manteniendo la rígida relación entre los signos que expresa la fórmula no interpretada.

Las ciencias fácticas no poseen símbolos vacíos, todos son símbolos interpretados. La racionalidad en la ciencia factual es necesaria, pero no suficiente; la sumisión en particular a algún sistema de lógica es necesario, pero no suficiente garantía para que el enunciado sea verdadero. Se exige además que los enunciados propuestos sean verificables en la experiencia, ya sea indirectamente - como en las hipótesis generales (v. gr., dado que la información se transmite y almacena en canales y "depósitos" de estructura material, tanto la capacidad de transmisión como la de almacenamiento ha de ser limitada) - o directamente - como en las consecuencias singulares de las hipótesis (v. gr., luego es de esperar pérdida de información u olvido como condición para nuevos almacenamientos). Tan sólo después de las pruebas de verificación podrá ser tomado como verdadero un enunciado y, aún así, sólo hasta nueva orden. Por este motivo la ciencia factual es llamada igualmente ciencia empírica, es decir, que la coherencia en las ciencias factuales es necesaria, pero no suficiente.

Pero tampoco la experiencia garantizará que la hipótesis en cuestión sea la única verdadera, pues sólo nos indica que es probablemente la adecuada. Llegamos, pues, a un conocimiento que es esencialmente probable o esencialmente "inconcluyente" y "no-final". La experiencia no demuestra, sino que únicamente verifica (la demostración es una operación lógicamente completa, mientras que la verificación es incompleta o temporaria) y los sistemas teóricos relativos a los hechos son esencialmente defectuosos.

Cuando en el discurso pedagógico se alude a la "verdadera educación", tal proposición no tiene otro sentido que el de mera aspiración o la convicción fiducial o ideológica. Indica que las metas educacionales son concordes con el marco simbólico general del contexto cultural, personal o colectivo en cuyo interior fueron formuladas. También indica el nivel de adhesión que a las mismas manifiesta el grupo humano que las mantiene, pero en ningún caso el término "verdadero" puede considerarse como indicador de validez epistemológica.

La Pedagogía es, por tanto, racional en el sentido de que ha de componerse de conceptos, juicios, raciocinios, no imágenes; el punto de partida y el de llegada son ideas y decisiones de acción. La racionalidad implica también que esas ideas pueden combinarse entre sí de acuerdo con algún conjunto de reglas lógicas para producir inferencias o nuevas ideas que habrán de ser corroboradas en la práctica. No se amontonan caóticamente sino que se organizan en sistemas, conjuntos ordenados de proposiciones o teorías; y la prueba de la argumentación se da, de hecho, en la actividad educativa tanto acudiendo al consenso experiencial críticamente razonado como a consecuencias razonables de experimentos científicos. Ello quiere decir que en estos procesos vitales y culturales vale para 
decidir la acción tanto la experiencia acumulada, si mantiene críticamente en la situación dada su valor de dirección de la acción, como la investigación de laboratorio, ya que en educación no podemos situarnos únicamente en el ámbito de la ciencia, sino en la totalidad del ámbito de la acción social exigida según el rol que competa a cada actor (padre, profesor) y no cabe inhibirse hasta que se decida racionalmente. En resumen, tan importante es dar a conocer lo que la ciencia produzca como fomentar la reflexión crítica para la toma de decisiones cuando la situación se dispara a quemarropa.

La Pedagogía científica, la investigación pedagógica, es un conocimiento objetivo, porque intenta concordar aproximadamente con la realidad fáctica y porque verifica la adaptación de las ideas a los hechos recurriendo a la observación y al experimento (controlable y reproducible); los hechos de la pedagogía son hechos del mundo y no búsqueda de expectativas de otro mundo.

Pero la Pedagogía científica no es meramente descriptiva o notarial; va más allá de los hechos, descartando muchos, recogiendo unos paquetes de propiedades y no otros en vistas a la racionalización de la experiencia; conjetura lo que hay detrás de la experiencia inventado conceptos que ni siquiera tienen correlato perceptual aún cuando se refieren a objetos, propiedades o relaciones, v. gr., $C=f t(\mathrm{P}, \mathrm{EV})$ no es un concepto empírico sino un principio que expresa una relación. No son, pues, los hechos por sí mismos sino su elaboración teórica y la comparación de las consecuencias de las teorías con los datos observacionales la principal fuente de descubrimiento de nuevos hechos.

La fórmula propuesta por Kurt Lewin " $C=f t(\mathrm{P}, \mathrm{EV})$ " indica que, en su planteamiento teórico, la conducta $(\mathrm{C})$ es función total de la personalidad (P) y del espacio vital (E.V.); los elementos de la fórmula no son hechos sino conceptos. En otra teoría, por ejemplo el psicoanálisis, se afirmaría que la conducta es función temporal de la personalidad y del espacio vital; la historia del individuo, sobre todo en sus etapas infantiles, es decisiva en la explicación.

De la práctica habitual de enseñar la lectura durante el período de escolaridad obligatoria, sentamos el convencimiento de que la edad para tal aprendizaje se sitúa en tal momento. Del planteamiento teórico de que los requisitos de la estructura cognitiva para el aprendizaje de la lectura son los mismos que los del aprendizaje del lenguaje oral, poseyendo ambos las mismas condiciones de ejercicio, se deduce la consecuencia, corroborada experimentalmente, de que se puede adelantar el aprendizaje de la lectura hasta los dos años, al menos.

La Pedagogía es analítica, es decir, aborda problemas circunscritos y trata de descomponer el todo fenoménico en sus elementos. Los problemas de la ciencia son parciales, aunque sus resultados sean generales, en tanto se refieren a clases de objetos. Este análisis es una herramienta de progreso: no ignora la síntesis sino en tanto que procedente de intuiciones que no cumplan los requisitos anteriores de racionalidad. Es mucho más que sentido común organizado. En contrapratida, la ciencia analiza los hechos y los descompone para obtener generalizaciones. La ciencia no desconoce o ignora el hecho individual o irrepetible, sino el hecho aislado. La única forma que tiene de acercarse a la esencia de las cosas es mediante el descubrimiento y la formulación de generalizaciones. De ahí que la aspiración 
del conocimieto científico sea alcanzar leyes, descubrir la legalidad de los fenómenos. De ahí también que la pretensión de componer una teoría general de la educación que tenga sentido ha de pasar por la declaración del marco de referencia de la misma. La tarea más habitual y urgente en las ciencias factuales, como la Pedagogía, es la de construir teorías particulares.

\subsection{Errores de perspectiva}

En función de lo que acabamos de decir, se dan dos equivocaciones frecuentes entre las personas de ocupación pedagógica. Por la primera, consideran que por el hecho de que cada alumno debe entenderse como un sistema de comportamiento absolutamente original e irrepetible no es posible plantear esquema de acción pedagógica que responda a enunciados legales o generalizaciones. Lo que en la mayor parte de los casos proporciona la irrepetibilidad de una situación son los valores únicos que adquieren las variables en función de las cuales se interpreta teóricamente tal hecho; pero, no obstante eso, la ley que rige las relaciones entre las variables puede ser mantenida. Por ejemplo, el sistema de intereses de una persona es absolutamente original, la motivación entre los alumnos de un aula se distribuye en forma dispar; en cualquier caso, sin embargo, se mantiene que el único elemento desencadenador de motivación y, al mismo tiempo, el único sobre el que se puede incidir técnicamente es la tarea que se ejecuta; luego, modificando la estructura de la tarea, podemos modificar el valor de la motivación y el interés. Esto es ya un enunciado generalizable que respeta perfectamente los caracteres del caso individual.

La segunda equivocación frecuente entre pedagogos es la de pretender, de entrada, en los trabajos teóricos acometer la elaboración de enunciados en cuyo campo de significación queden atrapados todos los aspectos del complejo fenómeno educación. Debemos ser más modestos y avanzar construyendo teorías de menor espectro semántico, más esqueléticas. En fenómeno tan complejo como el educativo pretender construir enunciados de tal poder de resolución nos lleva inexorablemente al campo de la imagen, la metáfora, la construcción mito-poética.

Por supuesto, no todos los hechos singulares conocidos han sido ni serán convertidos en casos particulares de leyes generales; sobre todo andamos muy a tientas en los procesos mentales superiores. Tal situación alimenta el prejuicio de que el comportamiento humano no es legal, sino aleatorio, no legal sino creativo. Tal vez debiéramos hasta cambiar de perspectiva para tratar con los fenómenos mentales y culturales; porque todavía en muchos curiosos de la mente se encuentra implícito el sueño ilustrado de construir la física experimental del alma (como si estuviéramos en la química del alma, donde mezclando unas acciones con otras, unas situaciones con otras, obtuviéramos el comportamiento). Cambiar la perspectiva, pero reconociendo la legalidad del comportamiento humano: ¿cómo se puede dar un sólo paso en el estudio del comportamiento si no se presupone que es legal?

La Pedagogía está característicamente orientada hacia la acción pedagógica, tiene como meta e intención elaborar criterios que rijan cursos de acción, pero ello 
no significa que no tenga pretensiones explicativas. Precisamente por su proyección activa comprueba, en mayor medida que en las situaciones meramente experimentales, las limitaciones de teorías científicas, las cuales no fueron construidas atendiendo a variables que únicamente la urgencia de la intervención práctica, en situaciones reales, convierten en relevantes. Por lo mismo, desde el imperativo de la acción pueden ser formulados problemas que requieran explicación o por lo menos criterios de decisión cuya confección puede tener como fundamento racional teorías elaboradas por la propia pedagogía o por ciencias afines.

A partir de lo anteriormente enunciado, la función previsora de la Pedagogía conviene ser explicitada. En la ciencia, la predictibilidad podría ser definida como la presunción de un hecho si se cumplen determinadas circunstancias, estipuladas por leyes. En el caso de la Pedagogía, y de otros cuerpos de enunciados referidos a la acción, la predictibilidad toma la forma de la previsión: dados unos enunciados científicos y una información específica sobre un sistema o situación educativa, si se acomoda el curso de acción a determinados enunciados normativos, entre los efectos posibles se incluirán los inicialmente proyectados. Más que predictibilidad de hechos o acontecimientos es previsión de eficacia respecto a la acción emprendida. Son importantes tales precisiones, ya que con frecuencia, dentro de las situaciones educacionales, quedan primadas las intenciones, la sublimidad o belleza de las propuestas finales; se olvida que de la intención no se deduce lógicamente el efecto o cambio en el sistema.

\section{Caracterización del REAlismo ingenuo en Pedagogía}

\subsection{Atribución teórica y atribución práctica}

Todo acontece en Occidente como si los hombres estuviesen divididos y contrapuestos en dos especies inhibridables: la de los hombres teóricos y la de los prácticos. En la distribución de roles, dentro de la trama social, un rol se contrapone a otro siguiente en la misma jerarquía que lo teórico y lo práctico, con tal que uno se dedique en forma dominante a proyectar y el otro ejecute. Pero tanto el proyectar como el ejecutar no son definibles absolutamente, sino tan solo de manera relativa. Para el ingeniero, el teórico es el político; para el contratista, el teórico es el ingeniero; para el capataz, el teórico es el contratista; para el obrero especialista, el teórico es el capataz; para el peón, es teórico el obrero. Se rompe la cadena en el eslabón en el que ninguno tenga oportunidad de otra actividad que la de la ejecución rutinaria.

Desde el punto de vista general, se supone que el hombre más habitual es quien actúa y vive prácticamente. También podemos afirmar que el hombre más dominado por el conocimiento ordinario es el que se tiene a sí mismo por práctico. El tejido inmediato de la materia, la acción, la necesidad son los que, para él, descubren el auténtico campo de significados. Los significados parecen inmanentes a los fenómenos, hechos, cosas con las que trasiega. Para este hombre práctico el motivo de su acción reverbera de la superficie material y, evidentemente, de la obra en la que interviene o de la cosa o sujeto sobre el que actúa. Por eso, a 
este modo de opinar se le denomina realismo ingenuo. El hombre práctico en el espacio pedagógico se supone que es el profesor, el animador..., hablaríamos, pues, de realismo pedagógico ingenuo.

\subsection{Notas del realismo ingenuo}

Desde la vertiente de la práctica tal realismo ingenuo se caracteriza por varias notas distintivas:

- Confusión entre estado real y estado natural. Pierde de vista que la conexión entre acción y motivo, entre situación e intervención, entre cosas y usos, entre acontecimientos y reacciones... son por y para el hombre, tienen su origen en él y en él termina su destino. El hombre tiene la tendencia a considerar que el estado real en el que se encuentra un sistema determinado es su estado natural, la mera consecuencia de las leyes físicas, biológicas o mentales que rigen en su estructura.

No advierte con facilidad que el ámbito de la educación es el mundo de fenómenos culturales, los que tienen lugar en el sobremundo, el mundo secundario de los proyectos humanos y su urdimbre social e histórica. La Pedagogía, en cambio, entiende que se pueden introducir modificaciones, intervenir en definitiva en tales fenómenos, por suponer que ninguno de ellos ha acontecido si no es porque cumple dos condiciones: la ser ser históricamente posible y la de ser naturalmente plausible.

De la segunda condición deduce la Pedagogía que, siguiendo la ruta que marcan las leyes descubiertas por la ciencia en el sistema de comportamiento humano, es posible diseñar cursos de acción en los que sea al menos tan probable la reproducción del estado real como la promoción del estado que se intenta como alternativa.

Que un fenómeno educacional, un estado de cosas en el proceso de desarrollo humano, sea puntual o habitualmente de una determinada manera tiene, pues, su origen en la legalidad de la estructura funcional que lo soporta (física, biológica o mental) y en la concreción cultural que las múltiples modalidades de configuración posible decantaron en cada caso. El realismo pedagógico ingenuo estima que la manera concreta de configurarse un comportamiento no obedece más que a leyes internas del sujeto, modos de ser, y no lo entiende como resultante reactiva frente al medio.

De ahí que no se sienta técnicamente interpelado ni personalmente comprometido. No es lo mismo una inflamación de laringe que volver a cometer el error probable de resolver un problema. Para lo primero sirve la terapia; para lo segundo, se impone un ciclo de acción modificado. En este segundo caso, el más afectado, a quien más directamente se dirige la "terapia" no es el paciente, sino el agente.

Cuando tenemos ante nosotros un niño no motivado para una actividad pedagógica, parece evidente que estamos ante una desestructuración motivacional ơ ante una disfuncionalidad motivacional objetiva. Aparece como la condición onto- 
lógica y natural de la realidad frente a nosotros: su apariencia. Sería "teórico", extraño, para esta perspectiva, considerar que tal modalidad de comportamiento es fruto de la trama activa que llevó al alumno hasta aquella situación suya respecto del aprendizaje, y fruto igualmente del diseño planteado para la tarea que tiene que realizar. Sin embargo, es mucho más especulativo el primer punto de vista que el segundo. El primero, el que atribuye todo a condiciones naturales, interpreta solamente; el segundo punto de vista, que concreta los procesos históricos en los que se implican sujetos, plantea, en sí mismo, la posibilidad de transformación de la realidad pedagógica advertida como problemática.

- Criterios de validez. Una segunda característica en la perspectiva del realismo ingenuo viene dada por el criterio de validez utilizado. El hombre prácticocorriente reduce el criterio de validez de la acción, del proceso, del acontecimiento... a la sola dimensión de la utilidad, de la ventaja directa e inmediata. Lo característico del realismo pedagógico práctico ingenuo es demandar ante el niño - por ejemplo- de bajo rendimiento iniciativas concretas de mejora (cambio de libro, cambio de escuela, castigo-recompensa), secuencias de acción concretas cuyo destino directo sea "in situ" aumentar el rendimiento. No se comprendería la validez práctica del estudio sistemático de las condiciones del aprendizaje significativo. La evidencia parece indicar que el fruto de esta actividad aumenta el conocimiento del profesor, pero no el rendimiento del alumno. La ventaja, respecto a la primitiva situación, es lejana e indirecta. El hombre práctico estructura la trama activa en la que se ve envuelto de manera que conceda seguridades, mantenimiento de estatus, estabilidad de rol... etc. Los elementos teóricos más atendidos serán aquéllos que racionalicen las causas culturalmente aparentes de tales estados de cosas.

Es el tópico cultural o gremial el más atendido, aquél que, en definitiva, mantiene los puntos de vista en función de los cuales se estructuran, aquí y ahora, las pautas de comportamiento.

- Desimplicación personal de la práctica. Es una manera de dependencia sensorial y de planteamiento protocientífico; de ahí que tales elaboraciones intelectuales, al tiempo que interpretan los hechos, mantienen y esclerotizan los cursos de acción. La modificación puntual de una norma práctica en la conducta pedagógica, sin la modificación sustancial de los puntos de vista con los que se considera la realidad, aumenta el grado de desimplicación personal sobre la situación.

Tal desimplicación personal arrastra dos actitudes o complejos de actitudes: de un lado, la del distanciamiento y retraimiento de la visión del sistema de enseñanza en su conjunto, de las visiones de totalidad. Nos referimos a la dificultad de aceptación, como punto de vista válido, de la perspectiva grupal y situacional de aula para el análisis de los comportamientos individuales; de la perspectiva institucional, para el planteamiento de la problemática del aula; de la visión sistémica comarcal, regional o nacional, para la problemática de la institución escolar; de la problemática sociocultural dominante, para la interpretación de la problematicidad del sistema escolar en su conjunto. Al carecer de actitudes para estas perspectivas 
se atascan los canales de iniciativas político-educacionales de distinto nivel, encerrándose el profesor en las incidencias puntuales, convirtiendo el cambio de incidencias en una necesidad cuya satisfacción ha de venir de fuera, y tergiversando, por ejemplo, la función de una estructura de equipo de apoyo hasta convertirla en farmacia.

- Desimplicación personal en el discurso pedagógico. Además, arrastrado por el complejo actitudinal anterior, surge otro: la falta de participación en el discurso pedagógico general con la voluntad de ser oído; se produce un abandono discursivo y una rigidización del comportamiento pedagógico práctico. El aislamiento del propio sistema de acción dentro de los límites de espacio concedido a la disciplina de que se es profesor. Aparecen resistentes a la observación externa, a la valoración de resultados, al análisis crítico sistemático de la acción pedagógica que se ejecuta. Se está abierto a la recepción de normas con efecto directo, visible e inmediato, pero no al análisis y diagnóstico del "ecosistema" en el que él es agente específico.

- La actividad teórica como actividad parasitaria. Otra característica de la mentalidad práctica es la de considerar la actividad teórica, cualquiera que sea la orientación y los contenidos de tal actividad, como función parasitaria. Evidentemente, la teoría o los recursos técnicos que se le ofrezcan al educador pueden ser absolutamente utópicos, en el sentido peyorativo del término, por no tener en cuenta el estado real de los agentes ni los estados reales de los sujetos sobre los que se interviene, lo cual es un defecto posible de las construcciones teóricas.

Pero lo que entendemos como realismo pedagógico práctico ingenuo es un fenómeno de reactividad compartamental, cuya característica es la dependencia respecto a los modos de acción y de intervención que produjo la práctica, en cuyo interior se consigue la seguridad socioprofesional. La teoría, en general, adquiere así la condición de elemento desestabilizador-desestabilizador cognitivo, porque produce conflicto conceptual y desestabilizador social, porque supone la aceptación de un nuevo rol dentro de la tesitura social en la que se encuentra prendido: el rol del apoyo teórico. Apoyo que, desde su punto de vista, siempre será teórico: nunca atenderá con debida precisión los datos que caracterizan los incidentes en los que él personalmente es protagonista, ya que son naturalmente irrepetibles y suponen un plus de destreza que es necesario adquirir (se acudía al apoyo precisamente por ser problemática la eficacia de la acción deducida de la experiencia personal), lo cual deja un vacío entre lo que se propone y lo que se dispone. Vacío que es imposible llenar; lo sabe todo técnico. Cada caso que tiene que resolver presenta caracteres diferenciadores a los del caso prototípico con el que se ilustró la teoría, cuando la estudiaba.

- Resistencia a la función de apoyo. De cualquier manera, la actitud que comentamos introduce un elemento a ser tenido en cuenta: la resistencia a la función teorética de apoyo. Resistencia, con fuerte carga emocional, que debe interpretarse como un dato más de la situación pedagógica problemática. Es muy frecuente encontrar a los agentes educativos en equilibrio respecto a los datos que 
configuran un conflicto cualquiera. Es la situación de conflicto instituido, en el que se han reestructurado todos los papeles del grupo en función del mismo. De ahí que sea altamente probable la intepretación de los comportamientos y papeles en conflicto como rasgos naturales de los actores implicados. Todos se encuentran ya cómodos, o por lo menos habituados a la situación conflictiva. Quien afirme (y por afirmarlo) que tales situaciones son superables, se entiende, en primera instancia, como teórico: alguien que parasita la circunstancia social conflictiva para vivir de ella, proponiendo alternativas y presentando la situación como originada por los actores y nunca como condicionamiento natural. La reacción más frecuente es la de sentirse interpelados como culpables, reacción claramente defensiva.

- Autosuficiencia. Es ésta una característica de la practicidad precrítica u ordinaria. Uno de los problemas más difíciles que tiene la Pedagogía es el de encontrar el hueco necesario para poder intervenir con eficacia. Por lo general, los patrones de conducta de los agentes educativos se encuentran estabilizados y acomodados al propio estilo de personalidad. De ahí que el coeficiente de inercia anidado en el corazón mismo del rol social sea muy alto.

Junto a la inercia advertida aparece el hecho de que la innovación más probable acontezca por presiones exteriores y no por movimiento endógeno. La intervención de un agente externo puede ser fácilmente prejuiciada. Así ocurre cuando el profesor sugiere medidas para el intracuerpo familiar, cuando el director escolar insinúa cambios en la derrota pedagógica del aula o cuando un pedagogo promueve iniciativas referidas a una institución. En todos los casos puede tener lugar un acentuamiento de la conciencia práctica precrítica en el sentido de la autosuficiencia, por entender que la circunstancia conflictiva o no, educativa en todo caso, se manifiesta de suyo, es por sí misma evidente, sin que revista carácter problemático alguno.

Tal dominancia de la dependencia sensorial y de la autosuficiencia satisface la necesidad interpretativa del hombre en su entorno social. El elemento invariable de tal compostura intelectual es el de la cerrazón sobre la apariencia descubierta en la práctica, olvidando que la apariencia es apariencia interpretativa, o interpretada y, por lo mismo, dependiente de posiciones teóricas y de perspectivas intelectuales.

Al cerrarse sobre sí misma, la práctica reniega de sus orígenes intelectuales: la crítica de la apariencia, puesto que toda práctica conllevó en un momento, antes de generalizarse y automatizarse, una actividad teórica más o menos elaborada. Lo que en un momento histórico sirvió de motor y cambio, se tornó en la fase siguiente en lastre y freno. Toda circunstanica educativa es dialéctica y debe estar animada por la crítica; toda apariencia es, aunque sensorialmente garantizada, intelectualmente insuficiente.

Por todos estos rasgos idiosincráticos de la práctica acrítica o precrítica se reproduce un distanciamiento entre teoría y práctica ${ }^{27}$, entre el rol de intervención prácti-

27. MAFFESOLI, M. (1985): La connaissance ordinarie. Précis de sociologie comprénbensive. Ed. Librairie des Méridiens, Paris. 
ca y el rol de producción de teorías, entre el hombre teórico y el hombre práctico. Cierto es que, de la misma manera que hemos dibujado la fisonomía de la práctica precrítica, podríamos también promover el escorzo de la teoría desrealizada.

No pretendemos aquí hacer coincidir al hombre práctico con el que trabaja "en la línea" de la enseñanza, frente al teórico o titulado en Pedagogía, que no pretende ser inmediatamente docente en áreas de conocimiento reglado, sino participar en "estructuras de apoyo" institucionalizadas o liberales, o no enseñar sino Pedagogía.

La contraposición entre teoría y práctica afecta también a los pedagogos, a todos los hombres que practican algún modo de acción social: todos y cada uno en su propio campo y con sus propios respectos. Tal contraposición no es una cuestión o problema práctico, sino teórico; no es un problema de la secuencia de acción, sino del modo de proceder intelectual en ella; y tal vez también pueda ser consecuencia intelectual del estado de la trama social en la que interviene el actor con sus acciones concretas.

\section{CONSECUENCIAS DE TAL CONTRAPOSICIÓN ENTRE TEORÍA Y PRÁCTICA}

\subsection{La alienación de la práctica}

La consecuencia teórica de tal estado de la práctica es muy importante. La práctica así entendida se distancia de sí misma. Se encuentra intelectualemtne extrañada, alienada. Aparece incapaz de reconocerse en su propia condición de agente histórico. Recrea, entonces, la figura de la ultradeterminación de la acción. Los estados de cosas se mantienen porque alguien o algo ajeno a tal práctica, mantiene, por propia decisión, tal estado de cosas. Cualquier teórico serio dirá, en materia pedagógica, que el arca que guarda los secretos y enigmas de la Pedagogía es el aula, el taller educacional, cualquiera sea su naturaleza. El por qué los niños fracasan en un aula especialmente diseñada para ellos se encuentra dentro del aula, allí ha de encontrarse la razón. Tanto si en ella se enseña como si se la apoya, en ella hay que mirar y hurgar. Llevar las causas a zonas situadas fuera, aunque fuera se produjeran los condicionamientos de un particular estado de cosas, es confesar a priori que, para esos estados, las instituciones educativas son impotentes. Puede que en determinados casos sea verdad, pero hay que demostrarlo.

No se podrá entonces hablar propiamente del progreso científico en Pedagogía, si no disponemos de aulas, espacios educacionales, donde real o simuladamente podemos apreciar el efecto de que, dada una secuencia de acción, entre los muchos acontecimientos que produzca, se encuentra o no el acontecimieto previsto. Tales aulas deben ser potencialmente todas, lo cual quiere decir que aquella aula en la que no se encuentra sembrada la elaboración intelectual que indaga las razones del éxito o del fracaso de los alumnos es un aula estabilizada en el máximo nivel de entropía y máximo índice de inercia.

Cuando el aula se mueve, inmediatamente se genera necesidad energética. Aquí, como en todos los sistemas humanos, la energía dominante no es el dine- 
ro, sino la información. Moverse es encontrarle un papel a la teoría, a la comprensión. Tales movimientos actúan a su vez de precipitadores y cristalizadores de teorías relevantes. Cambia entonces el aula su función y pasa de zona de aplicación de sus teorías a espacio para la validación y la producción histórica de la verdad teórica. Entonces son las aulas las que seleccionan y decantan las teorías históricas y socialmente relevantes de los puros juegos malabares.

Tales análisis nos llevan a consideraciones de carácter teórico e histórico de sumo interés: ¿¿uándo el acontecer en un área social determinada reclama urgentemente la renovación del pensamiento? ¿Qué circunstancias históricas se reproducen en aquellas épocas de máxima urgencia y estímulo para el pensamiento educativo? ¿Qué motivos coinciden para que tales pensamientos adquieran tal prestigio y poder social que incluso se lleven a su estipulación académica?

\subsection{Inductores sociales de la contraposición entre teoría y práctica}

En el prólogo mismo de la obra de J. Dewey, Experiencia y educación, señala el autor que «todos los movimientos sociales suponen conflictos que se reflejan en controversias". La separación entre teoría y práctica goza de rasgos que permiten las dos caracterizaciones: representan un conflicto derivado de un particular movimiento social y refleja el mismo en forma de controversia intelectual.

El movimiento social que reverbera en toda la controversia entre acción y pensamiento es aquél por el que se sancionan y adquieren status social las distintas formas de actividad dentro de los colectivos sociales.

Por todas partes se advierte la tendencia a la consideración de alguna forma de trabajo dentro de connotaciones que justifican el paso a otra como una forma de liberación. Tal forma de liberación se califica como ascenso. En la cúspide de la elevación, en la cima de los rangos no se encuentra otra forma de trabajo, sino el modo de vida de máxima calidad: vivir únicamente del espectáculo de la actividad de los demás. El pensamiento greco-latino dejó clavado en la sinfonía lingüística de la palabra trabajo tal condición de exasperación por la salida. La voz trabajar toma origen en el latín vulgar "tripaliare", torturar, con una especie de cepo formado con tres palos. De donde la verdadera fortuna no es la de encontrar trabajo, sino la de poder vivir sin trabajar. "Al que da Dios ventura e non la quier tomar.../ aya mucha lacería e cuita e trabajar" (J. Ruiz). El "Tripalium" era un lugar e instrumento en el que los reos sufrían tormento (alocus in quo rei verberanturn). Tal asociación entre vocablo y actividad no parece comprensible, si no se diera una asociación previa entre la actividad y la forma de ejecutarla.

El trabajo por excelencia no puede ser sino el manual y dependiente. Del mismo tan solo se advierte la condición de dominado y el frío y bruto esfuerzo rutinario y muscular. No se percibe la más mínima conexión entre tales actividades y aquellos otros episodios y decisiones que hacen cambiar los rumbos de la historia, transforman o destruyen las ciudades, proporcionan la gloria requerida para formar parte de un verso romance. No se presiente el poder de la acción, sino el poder del poderoso cuya acción es precisamente mandar que otros hagan.

(C) Ediciones Universidad de Salamanca

Teor. educ. 8, 1996, pp. 5-42 
En la decisión, en tanto que actividad meramente intelectual, y en todo el proceso que termina en ella, aunque tal decisión se encuentre en los mitos ultradeterminada por el hado ciego, es donde el hombre muestra la condición supraanimal que le define. El trabajo, pues, no solamente conllevará el esfuerzo y la penalidad, sino la indignidad y la connotación de esclavo. La libertad y la liberación se definirán por la línea de apartamiento de la necesidad de trabajar, por exclusión de la práctica material en la que la sobrevivencia está unida al esfuerzo manual.

\subsection{La investigación en la acción}

La actividad reflexiva humana se puede categorizar en función de dos finalidades mayores: explicar los acontecimientos y dirigir la acción. En principio, y para lo que aquí nos interesa, llamaremos a la segunda "reflexión práctica»28.

John Elliot distingue tres modos de reflexión práctica o conectada con la acción, y, como consecuencia, tres modalidades de investigación de este tipo: deliberativa o relacionada con la elección, posee carácter prescriptivo; evaluativa o relacionada con la respuesta, posee un carácter selectivo; la tercera, relacionada con el diagnóstico.

En la investigación deliberativa es donde se diseñan las metas a las que debe acercarse un ciclo de acción pedagógica; en la evaluativa es en la que se conoce si las metas fueron alcanzadas por los alumnos y los caminos por los que fueron conseguidas; la tercera establece la comprensión del estado en que se encuentran el sistema que configura el alumno, el profesor y la situación.

Es decir, que la reflexión que penetra la intervención pedagógica puede tener el sentido de conectar la respuesta obtenida con los propósitos planteados y juzgarla; elegir o seleccionar, en función de las circunstancias y procesos implicados conocidos, las estrategias y plantear el diseño técnico de la acción; o dilucidar las circunstancias que concurren para diagnosticar la tipología de la situación. El orden secuencial de un ciclo de acción pedagógica, construido con esos elementos, sería: diagnóstico-deliberación-evaluación.

La tendencia del científico positivista (por perspectiva epistemológica) o del "teórico irrealista" (por despiste o por exigencia de su "rol de enunciación") es convertir un acontecimiento pedagógico en un enunciado formal que lo transforma en caso particilar de un problema general o en ámbito particular de aplicación de una ley general.

La investigación en la acción, la reflexión del técnico, de aquél que tiene el cometido de tener que intervenir - de la manera más crítica y reflexiva posibleemplea, por el contrario, dos tipos de conocimiento: el que contiene las declaraciones e informes de los agentes implicados y el que se considera pertinente de entre el cuerpo de ciencia disponible. En ambos casos se requiere la meticulosidad y fidelidad al dato del científico. El primer tipo de conocimiento es funda-

28. Elliot, J. (1990): La investigación-acción en educación. Ed. Morata, Madrid. 
mental, porque para la ciencia el caso y la aplicación de la ley es un acontecimiento formal, mientras que el acontecimiento educativo es un evento social, compuesto por una trama tal de relaciones entre los elementos que la determinación de cuáles de ellos han de considerarse relevantes (diagnóstico), en vistas a la determinación de estrategias (deliberación), depende directamente del informe objetivo sobre el caso que se considera.

Evidentemente la capacidad de diagnóstico se establece a dos vertientes: la del agente, profesor o educador, que se ve interesado por todos los pormenores $\mathrm{y} / \mathrm{o}$ la del científico, que posee el conocimiento disponible para atribuir tales datos a clases así como para categorizar los diferentes componentes del acontecimiento descrito.

Las investigaciones llamadas de proceso-producto pretenden, por lo general, establecer las relaciones existentes entre las acciones pedagógicas y los resultados del aprendizaje en los alumnos. Encontrada, sin embargo, una relación positiva, correlación estadística, no se deriva que exista necesariamente vínculo causal entre una y otra. Antes al contrario, como criterio general, deberíamos hablar de que no es la enseñanza la que causa el aprendizaje. Este es el producto final de un proceso interior y predominantemente dirigido por estructuras y procesos interiores al propio alumno. El aprendizaje con éxito tiene la configuración de una experiencia intelectual de calidad en torno a unos contenidos. La práctica docente ha de concentrarse, pues, más que en el establecimiento de objetivos cada vez más atómicos, en el disñeo de tareas pedagógicas, en principios de procedimiento, metas pedagógicas, pertinentes y cualitativamente valiosas respecto a las diferentes modalidades de experiencias intelectuales que se proyectan. Los objetivos pedagógicos han de estipular más las condiciones de la acción pedagógica que las metas a conseguir por los alumnos. El aprendizaje no se alcanza por la acción pedagógica, sino en ella. Esto nos debe llevar a la necesidad de tener que replantear el significado del concepto de tecnología referido a la intervención pedagógica así como de cuanto significa aumentar nuestro conocimiento de la acción educativa. Tal es el contenido del problema que se expresa cuando se enuncia algo tan elemental en Pedagogía como que el alumno es el que causa el aprendizaje y que el educador es un instrumento. 